\title{
Os processos de desenvolvimento e desmatamento da Amazônia ${ }^{1}$
}

\author{
Rodolfo Coelho Prates ${ }^{2}$ \\ Carlos José Caetano Bacha ${ }^{3}$
}

\begin{abstract}
Resumo
Este artigo analisa - com base na revisão da literatura existente e por meio da análise de dados secundários, realizando uma análise histórica desde a Colonização Portuguesa - as etapas de desenvolvimento da Região Amazônica e sua associação com a prática do desmatamento, destacando as políticas públicas que fomentaram o desenvolvimento da região e o atual avanço de sistemas produtivos orientados pelo estímulo econômico. Demonstra-se que o desenvolvimento populacional e econômico da Amazônia, citados como as principais causas do desmatamento e estimulados, em boa parte, por políticas econômicas, é um processo desuniforme no tempo e no espaço, gerando o desmatamento desigual entre os estados que compõem essa região e dentro de cada estado.
\end{abstract}

Palavras-chave: Amazônia; Desenvolvimento; Políticas de desenvolvimento; Causas do desmatamento.

\section{Abstract}

The process of development and deforestation in Amazonia

Basing on the literature review and on published dataset and following the time chronology of the events since the Portuguese colonization, this paper analyzes the stages of Amazonian region development and its impacts on deforestation, highlighting the policies addressing to foster the Amazon's development and the current stage of economic activities. The population growth and the economic activities, pointed out as the main causes of the Amazonian deforestation and stimulated by economic policies, have been unequally developed inside the Amazonian region, generating the unequal deforestation process among the Amazonian states and inside each state.

Keywords: Amazonian region; Development; Development policies; Deforestation causes. JEL N980, Q240, R200, R500.

\section{Introdução}

A região da Amazônia abriga a última floresta de dimensão continental no mundo (Ross, 2006) e identifica, quanto ao seu uso, no mínimo, dois grupos de atores: um com interesse no grande potencial de recursos, visando, dessa forma, sua extração e transformação e outro com interesse em sua preservação. Tais interesses poderiam ser conciliatórios, como demonstrado pelas indústrias

(1) Trabalho recebido em 10 de novembro de 2008 e aprovado em 21 de julho de 2010.

(2) Professor do Programa de Mestrado e Doutorado da Universidade Positivo (UP), Curitiba, PR, Brasil. E-mail: rdlps@bol.com.br.

(3) Professor Titular da Esalq-USP (Escola Superior de Agricultura Luiz de Queiroz da Universidade de São Paulo), Piracicaba, SP, Brasil. E-mail: cjcbacha@esalq.usp.br. 
farmacêuticas e de empresas biotecnológicas e de engenharia genética, que manifestam o desejo de que a Amazônia ofereça o que tem, mas que fique em seu lugar com suas características intactas (Souza, 2002).

No entanto, não é isso que vem ocorrendo na região. $\mathrm{O}$ modelo de desenvolvimento da Amazônia implica sua transformação, ou seja, a manutenção das características naturais e o desenvolvimento são elementos dissociativos, no qual este último compete e se sobrepõe àquele.

A região passou por diversas fases de desenvolvimento. Durante a colonização portuguesa no Brasil, houve algumas tentativas de instalar alguma atividade para extrair ou gerar riqueza, mas que foram impossibilitadas pelas dificuldades naturais da região, restando apenas núcleos em pequenas áreas. $\mathrm{O}$ mesmo aconteceu no período do Império.

Desde o final do século XIX, é possível identificar quatro grandes processos que deram sentido à ocupação territorial da Amazônia. O primeiro é marcado pela influência internacional, quando a região se inseriu no mercado internacional por meio da produção e exportação da borracha; o segundo é caracterizado por intervenções esporádicas do governo federal, no momento em que a região passou por certa indefinição econômica; o terceiro se mostra quando o Estado Nacional escolhe a região para ser o grande palco de suas ações de planejamento territorial e, finalmente, o quarto é caracterizado pela conjugação de ações estatais, embora em menor escala que no período anterior, e pelo avanço dos agentes impulsionados pelas forças de mercado internas e também externas.

Tendo em vista essa dinâmica histórica da Amazônia, o objetivo deste artigo é analisar, com base na revisão dos trabalhos já realizados e por meio da análise de dados secundários, as etapas do processo de desenvolvimento da Região Amazônica e sua associação com a prática do desmatamento, destacando as políticas públicas que fomentaram a ocupação da região e o atual avanço de sistemas produtivos orientados pelo estímulo econômico. Procura-se demonstrar que o desenvolvimento da Amazônia é um processo desuniforme no espaço, gerando o desmatamento desigual entre os estados que compõem essa região e dentro de cada estado.

O presente artigo compõe-se de mais seis itens, além dessa introdução. $\mathrm{O}$ item 1 revê a literatura referente ao assunto em análise. $O$ item 2 analisa, seguindo a cronologia histórica, as grandes linhas que nortearam o processo de desenvolvimento da região. $\mathrm{O}$ item 3 descreve as políticas de incentivos fiscais e de linhas de créditos que foram adotadas, em especial a partir da década de 1960, para estimular as atividades econômicas na Amazônia. O item 4 analisa as variáveis que são citadas na revisão da literatura como causas imediatas do 
desmatamento. $\mathrm{O}$ item 5 evidencia, por meio do uso de dados secundários, $\mathrm{o}$ processo de desmatamento desigual da Amazônia Legal. O artigo se encerra com as considerações finais.

\section{Revisão bibliográfica}

Por se constituir em uma região ampla, com muitas possibilidades de extração de recursos e possuir a maior floresta equatorial do mundo, a Região Amazônica sempre despertou a atenção de muitos pesquisadores que geraram, ao longo de várias décadas, uma quantidade considerável de trabalhos. Nesta seção é apresentado um panorama geral dos trabalhos que tratam dos temas discutidos nesse artigo.

A articulação da Amazônia com as demais regiões do Brasil sempre foi tênue e despertou, em função dessa condição, grande interesse para que ela se integrasse ao restante do Brasil. Antes das próprias ações governamentais, teóricos, principalmente militares, esboçavam a relação da Amazônia com as demais regiões brasileiras (Meira Mattos, 1980; Couto e Silva, 1981; Costa, 1992). Além dos trabalhos de natureza teórica, muitos outros surgiram para oferecer suporte técnico ao avanço do desenvolvimento da região. A esse respeito, consultar Serrão et al. (1978) e Reis (1978), por exemplo.

A constatação da necessidade de integração gerou um conjunto de políticas governamentais para torná-la efetiva. Para tal finalidade, o governo federal elaborou grandes projetos de rodovias que propiciavam o estímulo à imigração e à formação de atividades econômicas, como a Belém-Brasília (Goodland; Irwin, 1975), a Cuiabá-Santarém, a Cuiabá-PortoVelho-Manaus, a Perimetral Norte e a Transamazônica, todos inseridos no Programa de Integração Nacional - PIN, que ocorreu na primeira metade da década de 1970 (Kohlhepp, 2002). Por outro lado, muitos trabalhos mostram as formas que o governo utilizou para dinamizar economicamente a região por meio de investimentos próprios ou via concessão de incentivos fiscais e fundos de investimento, visando atrair capitais privados (Becker, 2000, 2001, 2005, 2007; Serra; Fernández, 2004).

Um dos primeiros trabalhos a quantificar o fluxo migratório para a região no início do Ciclo da Borracha foi o de Furtado (1991). Posteriormente, outros evidenciaram a dinâmica populacional da região (Benchimol, 1999; Moreira; Moura, 1998).

Especificamente, sobre o desempenho do setor madeireiro na Amazônia, Figueiredo, Lopes e Filgueiras (2005) concluíram que, dado o lucro elevado do setor, a exploração da floresta e, consequentemente, o desmatamento devem continuar. 
Dada a imensa disponibilidade de terras para o cultivo na região, muitos trabalhos focam sobre o seu sistema agropecuário (Nascimento; Homma, 1984; Menezes, 2002; Brandão; Rezende; Costa Marques, 2005). Homma (2003) analisou o surgimento da agricultura e seu avanço na região. A adaptação da agricultura familiar às características naturais do bioma amazônico é retratada por Homma (2006) bem como a dualidade entre agricultura empresarial e familiar na região.

Théry (2002) salienta a fraca articulação interna da região, justificando que as unidades federativas que formam a Região Norte têm fluxos comerciais mais intensos com unidades federativas de outras regiões do que com elas próprias. Isso também é ressaltado por Silva, Rodriguez e Guilhoto (2004) e por Guilhoto e Sesso Filho (2005).

O desenvolvimento da Região Amazônica e a expansão de atividades produtivas geraram o desmatamento de sua floresta. Um dos trabalhos precursores e específico sobre o desmatamento é o de Tardin et al. (1979). Após este trabalho, surgiram outros, indicando as razões para o desmatamento. Embora alguns apontem enfaticamente para fatores específicos, como a construção e pavimentação de estradas ou outras melhorias em infraestrutura (Laurance et al., 2004; Soares Filho et al., 2005; Weinhold; Reis, 2003), o avanço da pecuária (Margulis, 2003) para atender os mercados internacionais (Kaimowitz et al., 2004) e da soja (Brandão; Rezende; Marques, 2005; Fearnside, 2006) ou até mesmo o crescimento populacional, pode-se constatar que todos estão plenamente relacionados ao desmatamento. Diante de problemas que o desmatamento traz ao meio ambiente, surgem trabalhos que visam oferecer sustentabilidade ambiental para as atividades econômicas na região (Reydon, 1997) e, numa escala mais ampla, que propõem o zoneamento ecológico econômico da região (Rebello; Homma, 2005).

A contribuição do presente artigo é analisar a relação entre os processos de desenvolvimento e de desmatamento da Amazônia Legal, ressaltando que são espacialmente desiguais entre e dentro dos estados que compõem a Amazônia Legal. Para tanto, utilizam-se as informações constantes na literatura supraanalisada e adicionam-se novas informações.

\section{O sentido do desenvolvimento da Amazônia: intervencionismo, controle estatal e estímulos de mercado}

Divide-se, para efeito desse artigo, o período de ocupação e de desmatamento da Amazônia em cinco fases. A primeira abrange o período colonial do Brasil (item 2.1). A segunda fase engloba o Período Imperial e o $1^{\circ}$ ciclo da borracha (item 2.2). A terceira fase vai da década de 1920 a meados da 
década de 1960 (item 2.3). A quarta fase abrange os governos militares de 1966 a 1985 (item 2.4). A quinta fase compreende o período a partir de 1986 (item 2.5).

\subsection{A colonização portuguesa da Amazônia}

É consenso que o início da colonização portuguesa na Amazônia ocorreu com a fundação de um núcleo urbano em 1616, tornando-se, posteriormente, na cidade de Belém. Em 1622, introduziu-se a atividade da pecuária e, em 1634, entrou em funcionamento o primeiro engenho na região para a fabricação de açúcar (Homma, 2003). Uma agricultura diversificada para os padrões da época, embora incipiente, foi inicialmente praticada por um grupo de famílias açorianas que chegou a Belém em 1676. Tal agricultura consistia no cultivo de arroz, tabaco e cacau (Homma, 2006).

A estratégia da Coroa Portuguesa era, basicamente, ocupar o território, independente do uso que poderia ser dado a ele. De forma a ter um aproveitamento econômico, tentou-se a implantação da cultura da cana-de-açúcar, atividade que se mostrou infrutífera na região devido às condições naturais desfavoráveis ao desenvolvimento dessa gramínea (Prado Júnior, 1993). Como afirma Furtado (1991, p. 153), ao longo do século XVII "as colônias da região norte ficaram abandonadas aos seus próprios recursos e as vicissitudes que tiveram de enfrentar demonstraram vivamente o quão difícil era a sobrevivência de uma colônia de povoamento nas terras da América".

Durante o Período Colonial, é possível afirmar que o desmatamento na região estava localizado em pontos isolados, nas margens dos principais rios, sempre em pequenas extensões. No Estado do Pará, o desmatamento ocorria nas proximidades de Belém, em função de constituir-se, neste estado, a primeira aglomeração populacional na região, pela presença das atividades da agricultura e da pecuária e por ser o local do primeiro engenho de fabricação do açúcar no Estado do Pará, demandando terras para o cultivo da cana-de-açúcar. Além de Belém, o desmatamento ocorria nos núcleos urbanos de Bragança, Ourém e Paru. No atual Estado do Amapá ocorreram pequenas áreas de desmatamento decorrentes da colonização em Macapá. No Estado do Amazonas, o desmatamento ocorreu na cidade de Manaus e nas áreas destinadas aos cultivos de cacau, café e tabaco, principalmente em Curupá.

\subsection{Do Império ao Ciclo da Borracha}

Até o final do século XIX, a Região Amazônica experimentou um relativo crescimento com as culturas do algodão, do arroz e do cacau. No entanto, esse crescimento não foi suficientemente vigoroso para promover uma fase sustentada de desenvolvimento. 
Já no final do século XIX e início do século XX, o produto de maior destaque na região foi a borracha, que teve uma elevada demanda decorrente da implantação do setor automobilístico na Europa e nos Estados Unidos.

Dadas as características naturais da região e da organização produtiva, o aumento de produção da borracha dependia tão somente da quantidade de mão de obra utilizada. O período de secas no Nordeste, entre 1887 e 1890, fez com que governo federal estimulasse um grande fluxo de trabalhadores do Nordeste para a Amazônia. Furtado (1991) registra que cerca de 260.000 pessoas migraram para a Região Norte no último decênio do século XIX, predominantemente atraídos pelo Ciclo da Borracha. Além do mais, como a região necessitava importar bens de outras regiões do país e de outros países, em 1903 foi inaugurada a Estrada de Ferro Belém-Bragança com o objetivo de transportar alimentos até os seringais. Em 1903 e 1907 iniciaram-se, respectivamente, as obras das estradas de ferro Tucuruí e Madeira-Mamoré (Homma, 2006).

O surgimento e o crescimento da produção da borracha possibilitaram o povoamento ao longo dos principais rios da região, o que fez surgirem várias cidades ou vilas. A atividade de produção da borracha pouco gerou o desmatamento, devido às características de extração e beneficiamento do látex. No entanto, como se poderia esperar, o surgimento de núcleos urbanos gerou diretamente o desmatamento devido à construção do espaço urbano e para a extração ou produção de bens (que não eram oriundos de outras regiões) destinados a atender predominantemente a população local. Se na fase anterior o desmatamento estava concentrado em alguns pontos, agora ele se torna disperso por boa parte da região, mas sempre próximo aos rios, que eram os únicos meios de transporte na época. As construções das ferrovias Belém-Bragança, MadeiraMamoré e Tucuruí também propiciaram o desmatamento ao longo de seus traçados. Além disso, as colônias de japoneses nos municípios de Parintins (no atual Estado do Amazonas) e Tomé-Açu (no Pará) para o cultivo da juta e da pimenta-do-reino, respectivamente, também geraram pontos de desmatamento no centro da floresta amazônica.

A partir da segunda década do século XX, o Ciclo da Borracha entrou em crise, promovida pela concorrência da produção de países asiáticos. Para amenizar os efeitos da crise, em 1912 foi criado o Plano de Defesa da Borracha, tendo como órgão responsável por sua execução a Superintendência de Defesa da Borracha, subordinada ao Ministério da Agricultura, Indústria e Comércio. O Plano visava retomar a inserção da borracha brasileira nos mercados internacionais. "Além de preconizar a modernização da extração, beneficiamento, transporte e comercialização do produto, o plano pretendia tornar mais racional o processo de trabalho, por meio de medidas de saneamento e assistência médica que 
mantivessem nos limites normais o coeficiente de mortalidade absurdamente elevado" (Benchimol, 1990, p. 42).

Segundo Miranda Neto (1991), a criação da Superintendência de Defesa da Borracha e a elaboração do Plano de Defesa da Borracha constituíram as primeiras intervenções do governo federal na região que visavam o crescimento econômico bem como a elevação das condições de vida da população local. No entanto, a escassez de capital privado, a pequena dimensão do mercado interno e, principalmente, a fragilidade financeira do Estado não permitiram atingir a contento os objetivos do Plano.

Passada a fase áurea do Ciclo da Borracha, a atividade econômica ficou concentrada nas duas maiores cidades da região, Manaus e Belém, que detinham uma indústria pouco evoluída de transformação de produtos provenientes da atividade de extração, além de um incipiente comércio.

\subsection{O novo ciclo da borracha na Segunda Guerra Mundial e seus desdobramentos}

A borracha tornou-se novamente importante para a economia da Região Amazônica no período da Segunda Guerra Mundial, quando os japoneses interromperam a produção da Malásia. Nesse período, com o auxílio dos Estados Unidos na criação de infraestrutura e com o estímulo da produção para atender aos fins militares, formalizados nos Acordos de Washington, o governo de Getúlio Vargas estimulou uma grande operação de extração do látex na região, operação, esta, que ficou conhecida como a "Batalha da Borracha".

Em 1943, foi criado, em Fortaleza, o Serviço Especial de Mobilização de Trabalhadores para a Amazônia - Semta. Dessa forma, o governo conseguia minimizar o impacto da seca no Nordeste, gerando um novo fluxo de trabalhadores nordestinos para a extração do látex na Amazônia.

Nesse mesmo período, foram criados o Serviço de Navegação da Amazônia e de Administração do Porto do Pará (Snapp), a Superintendência para o Abastecimento do Vale da Amazônia (Sava) e o Banco de Crédito da Borracha, todos com o objetivo de dar suporte à ampliação da produção da borracha, que deveria atingir 45 mil toneladas anuais, volume estipulado nos Acordos de Washington. Durante a vigência desses acordos, houve estímulo ao crescimento da produção de borracha, mas esse crescimento foi incapaz de gerar desdobramentos em outros setores.

Com o fim do Estado Novo no Brasil, uma reforma da estrutura legal do país foi necessária, o que ocorreu com a Carta Constitucional de 1946. No seu artigo 199 é ressaltado, em linhas gerais, que a União aplicaria, durante 20 anos 
consecutivos ou mais tempo, quantia superior a $3 \%$ de sua receita para a valorização econômica da Amazônia, sem mencionar diretrizes, setores ou regiões nos quais tais recursos deveriam ser aplicados. Além disso, a Carta Constitucional, no seu artigo 156, permitia que os posseiros localizados em terras devolutas pudessem comprá-las, desde que a área total não ultrapassasse 25 hectares.

O artigo 199 da Constituição Federal de 1946 ganhou forma e significado por meio da Lei 1806/1953, com a criação, em 1953, da Superintendência do Plano de Valorização Econômica da Amazônia (SPVEA), que tinha como meta a promoção do desenvolvimento agropecuário e a integração da Amazônia com as demais regiões do país. Esta lei também criou a denominação Amazônia Legal para ser uma unidade de planejamento do território nacional.

Segundo Cardoso e Muller (2001, p. 58), a SPVEA pretendia "proceder à seleção de espaços econômicos mais propícios ao desenvolvimento, onde pudessem estabelecer-se pólos de crescimento cujos efeitos se irradiassem por uma área maior".

De todo o conjunto de medidas idealizadas pelo Plano de Valorização Econômica da Amazônia, apenas houve o avanço de alguns pontos no setor energético e a construção das rodovias Belém-Brasília e Brasília-Acre, conectando o Centro-Sul à região norte do país pelos seus contornos. Em termos práticos, a construção das rodovias criava a "civilização de terra firme", contrastada com a tradicional "civilização de várzea" (Homma, 2006).

Tais ações estavam em consonância com os propósitos do planejamento regional, ainda em fase embrionária no período de 1930 a 1960 (Homma, 2006). Embora, como ressalta Becker (2001), muito mais discursiva do que prática, tais ações, principalmente a implantação das rodovias, estimularam ainda mais o fluxo de migrantes, gerando, no período de 1950-60, um salto populacional de 1 milhão para 5 milhões. Além disso, desestruturaram a pequena indústria local e propiciaram a competição com produtos agrícolas do Sul (Homma, 2003).

O principal elemento que deu condições para a ampliação do desmatamento na região foi a construção das rodovias Belém-Brasília (BR-010) e Brasília-Acre (BR-29, atualmente BR-364). Esses dois grandes eixos rodoviários permitiram a formação de muitos povoados, vilas e cidades que, adotando como atividade econômica a agricultura e a pecuária em áreas próximas a essas rodovias, culminaram no desmatamento ao longo dos mesmos. Além desses desmatamentos, ressalta-se a expansão das culturas de juta nas várzeas de alguns rios da região e também a ocupação das várzeas do rio Guamá, no Estado do Pará, para a produção de alimentos, aumentando as áreas desmatadas. Com a exceção das novas rodovias construídas e outras situações isoladas, até a década de 1960, o 
desmatamento esteve concentrado em áreas de várzea dada a predominância do sistema de transporte por meio dos rios.

\subsection{O controle estatal: 1966 a 1985}

A partir de 1966, a Região Amazônica passou a ser contemplada por várias ações do governo federal, que assumiu um caráter centralizador e planejador. Isso deve-se, em parte, à visão que os militares tinham a respeito da Amazônia, que pode ser resumida de acordo com o pensamento do general Golbery do Couto e Silva, de que a região era um imenso espaço desigualmente ocupado e carente de integração. O governo militar enxergava a região como "um vasto arquipélago" (Couto e Silva, 1981) desintegrado das demais regiões do país, o que, segundo ele, implicaria um grande perigo à integridade do território nacional.

Além do mais, os militares enxergavam o território como um importante elemento de controle, pois, por meio dele, garantiam inclusive o controle social. Para isso, era necessária a construção de infraestruturas, servindo de conexão aos diferentes pontos existentes, garantindo a coesão interna e a manutenção da integridade territorial (Costa, 1992). O conjunto de vias de transporte, denominado malha programada, garantia "a apropriação física e o controle do território" (Becker, 2001).

Especificamente, segundo Becker (2001), o Estado entendia que a região era prioridade pelas seguintes razões: a) a solução para conflitos sociais decorrentes da modernização da agricultura nas demais regiões do país; b) o palco de ações de resistência contra o governo militar; c) pela insegurança nas áreas fronteiriças; e d) preservar a soberania nacional sobre a região.

Para a implementação de um controle mais rigoroso, havia a necessidade de modernizar o aparato institucional do Estado voltado à Região Amazônica, que deveria contar com instituições capazes de responder prontamente às orientações políticas. Nesse sentido, o Banco de Crédito da Borracha foi transformado no Banco da Amazônia S.A. (Basa) e a Superintendência do Plano de Valorização Econômica da Amazônia (SPVEA) foi transformada na Superintendência de Desenvolvimento da Amazônia (Sudam). Além dessas transformações, houve a criação da Superintendência da Zona Franca de Manaus (Suframa), que se constituía como um enclave tecnológico no meio da floresta, propiciado por grandes incentivos fiscais.

Os militares sempre consideraram a Região Norte estratégica, tanto que ela esteve presente em todos os grandes programas engendrados pelo governo, tais como o Programa de Integração Nacional (PIN), o Programa de Redistribuição de 
Terras e Estímulo à Agroindústria do Norte e do Nordeste (Proterra), Plano de Desenvolvimento da Amazônia (PDA), Metas e Bases ${ }^{5}$, I Plano Nacional de Desenvolvimento (I PND) e II Plano Nacional de Desenvolvimento (II PND). Por ser uma região estratégica, o Estado se propôs a implantar redes de integração espacial, tais como:

- Construção da rede rodoviária, impulsionada pela Transamazônica, Perimetral Norte, Cuiabá-Santarém e Porto Velho-Manaus;

- Ampliação da rede de telecomunicação, por meio de satélites, proporcionando acesso à televisão aberta, e pela expansão de linhas telefônicas;

- Melhoria da rede urbana, que serviria de suporte às instituições estatais e organizações privadas;

- Construção da rede energética, fundada em hidroelétricas, que serviria como insumo à nova fase industrial.

Além do aparato físico, o Estado elaborou medidas para garantir maior presença humana na Amazônia. Nesse sentido, o Estado estimulou uma corrente migratória por meio dos projetos de colonização. Ademais, foram adotadas medidas fiscais e creditícias visando atrair capitais, primordialmente os ligados à exploração dos recursos naturais ali existentes.

Em relação à agricultura, o governo federal passou a incentivar projetos de estímulo ao desenvolvimento dessa atividade no norte do Estado do Mato Grosso e no sul do Estado do Pará. Além disso, nos anos de 1965 e 1966, foram criadas, respectivamente, nos Estados do Pará e do Amazonas, as Associações de Crédito e Assistência Rural (Acar).

Com a crise econômica gerada pelo Choque do Petróleo em 1973, o governo teve que reorientar sua estratégia de desenvolvimento na Região Amazônica, pois as que vinham sendo adotadas se mostraram excessivamente onerosas. Tal alteração culminou, em 1974, com a criação do Polamazônia, em que cada polo de desenvolvimento constituía um tipo de produção especializada. Dentro dessa estratégia, o governo "estimulou imigrantes dotados de maior poder econômico, resultando na expansão das empresas agropecuárias e de mineração" (Becker, 2001). Assim, o governo garantia a continuidade do desenvolvimento amazônico sem despesas excessivas de recursos.

É em meados da década de 1970 que se inicia o questionamento sobre o desmatamento na Amazônia, quando mais de 10 milhões de hectares já haviam sido desflorestados. Devido à constatação dos problemas ambientais, em 1979

(5) Programa Metas e Bases: programa divulgado em 1o de outubro de 1970, que delineava a ação do governo no período entre 1970 e 1973. 
firmou-se a cooperação científica internacional na Amazônia por meio do convênio com a Deustche Gesellschaft für Technische Zusammenarbeit - GTZ, da então Alemanha Ocidental, visando a utilização adequada dos solos e sua conservação.

No começo da década de 1980, com a segunda crise do petróleo, o governo decidiu rever drasticamente suas ações na região, visando reduzir as despesas públicas. Tal premissa resultou na concentração de recursos em poucas e selecionadas áreas com o intuito de fomentar as exportações da região, a exemplo do Programa Grande Carajás e o Projeto Calha Norte. Além desses, destaca-se o Polonoroeste, que foi implementado, em 1982, em Rondônia e no norte do Mato Grosso. Essa ação do governo federal contou com o financiamento do Banco Mundial e visava absorver um contingente populacional de outras regiões por meio da melhoria da infraestrutura, do aumento da produtividade agrícola, da geração de renda das atividades agropecuárias e, consequentemente, da melhoria do bem-estar de sua população (Serra; Fernández, 2004).

As ações encadeadas pelo governo federal resultaram em três grandes concentrações econômicas, diferenciadas tanto em termos de localidade como também em termos de natureza produtiva. São elas:

1) o triângulo formado por Carajás, Belém e São Luiz, apoiado na rodovia Belém-Brasília, em trechos da Transamazônica e na ferrovia Carajás, baseado na economia metropolitana e de exploração mineral;

2) a Zona Franca de Manaus;

3) a faixa agropecuária meridional que se expande ao longo das rodovias que circundam a região, desde o sudeste do Pará ao Acre” (Becker, 2000).

O governo federal tinha a premissa de que os subsídios fiscais iriam atrair os capitais privados à Amazônia, constituindo um elemento sustentado de desenvolvimento à região. O interesse que governo demonstrava pela região, naquele momento, pode ser visto pela quantidade de recursos públicos e privados que foram deslocados para a Amazônia, os quais superaram os do Nordeste, mesmo com estes contando com maior poder político (Teixeira, 1998).

É exatamente ao longo desse período que o desmatamento começou a se intensificar na região, culminando, em meados da década de 1980, em cerca de $10 \%$ de área da floresta já desmatada. E isso ocorreu por várias razões. A implantação de grandes projetos agropecuários apoiados por incentivos físcais passou a existir no sul do Estado do Pará e no norte do Estado de Mato Grosso, estimulando a ocupação da região e aprofundando a retirada da cobertura florestal. As construções das rodovias PA-70, entre a cidade de Marabá, a rodovia Belém- 
Brasília e a Transamazônica (BR-230) criaram um novo eixo de desmatamento em porções centrais da floresta. Além disso, as políticas promovidas pelo Instituto Nacional de Colonização e Reforma Agrária (Incra) também contribuíram para a retirada da cobertura nas áreas de assentamento ao longo das principais rodovias que cortam a região, principalmente nos estados de Rondônia, Mato Grosso e Pará.

\subsection{O desenvolvimento da Amazônia no período de 1986 até 2008}

Após o fim do governo militar, em meados da década de 1980, a situação financeira do Estado estava fragilizada em função da chamada crise da dívida externa. Isso se desdobrou na diminuição de alguns investimentos do governo na Região Amazônica. Paralelamente, a Amazônia despertou a atenção internacional, principalmente dos Estados Unidos e da Europa, que reivindicavam a preservação da floresta. Diante de tais pressões, o governo do presidente José Sarney criou o Programa Nossa Natureza em 1988. No ano seguinte, foi criado o Instituto Brasileiro do Meio Ambiente e dos Recursos Naturais Renováveis (Ibama).

É ao longo da década de 1990 que o dilema entre as políticas de desenvolvimento na Região Amazônica e a preservação de suas florestas se tornou mais explícito. Entre as políticas mais notórias de desenvolvimento pode-se citar os programas Brasil em Ação, de 1996, e o Avança Brasil, de 1999, em um nível mais abrangente. Junto a eles, ocorreu o início do transporte da soja pela hidrovia do rio Araguaia em 1995 e a inauguração da hidrovia do rio Madeira em 1997, em um nível mais específico. Por sua vez, é nessa mesma década que ocorreram o PPG7, a United Nations Conference on Environment and Development (RIO 92) e a assinatura do Protocolo de Kyoto.

Em 1991, o Brasil negociou, em Genebra, o Programa Piloto para Proteção das Florestas Tropicais Brasileiras (PP-G7), que foi lançado oficialmente em 1993. O programa - financiado pelos países da União Europeia, Canadá, Estados Unidos e Japão - aprovou recursos que totalizaram US\$ 250 milhões e constitui-se no maior projeto ambiental de cunho externo implementado em um único país até aquele momento. Até 2008, segundo o Ministério do Meio Ambiente, o programa demarcou 149 áreas indígenas, estabeleceu 2,1 milhões de hectares de reservas extrativistas, implementou 190 projetos de produção sustentáveis, treinou cerca de 12 mil pessoas para combater incêndios e realizou 53 projetos de pesquisa básica e aplicada.

Em 1996, com o Programa Brasil em Ação e, posteriormente, com o Programa Avança Brasil (PAB), foi retomado o modelo exógeno de crescimento da região, com a proposição de corredores de desenvolvimento regional baseados na consolidação de vias de transporte. Dessa forma, o modelo anterior para o 
desenvolvimento regional foi resgatado, pois tais programas revivem a mobilização extensiva de recursos naturais.

Nesse mesmo ano, o governo federal editou a Medida Provisória n. 1.511 de 25 de julho de 1996, motivado pelas muitas pressões sobre o desmatamento na Amazônia. Esta Medida Provisória elevou de 50\% para 80\% o limite das áreas de reserva legal dentro dos imóveis rurais situados na floresta amazônica.

Uma outra política importante para a região é o Plano Amazônia Sustentável (PAS), lançado pelo governo federal em 2006. Nele, o governo reconhece o "esgotamento das políticas públicas de ocupação do território" (Brasil, 2006, p. 10) e orienta a ação do Estado (diretrizes), visando a promoção do ordenamento territorial, a minimização do desmatamento, a agregação de valor à produção regional, a estimulação do desenvolvimento com equidade, a cooperação entre os estados da região com os demais entes federados e o fortalecimento da sociedade civil.

Pelas diretrizes do PAS, pode-se perceber claramente a postura atual do Estado, que se insere como um dos vários agentes que interagem na região, cujo papel principal é a articulação com os demais setores da sociedade. O presente engajamento contrasta fortemente, como foi visto no item anterior, com a atuação de um Estado centralizador e gestor no período que estende de meados da década de 1960 a meados da década de 80 .

\section{As políticas de isenções fiscais e de linhas crédito para dinamizar as atividades econômicas na região Amazônica}

Para estimular as atividades econômicas na Amazônia Legal, o governo federal, além dos investimentos em infraestrutura (como a construção de rodovias) e dos projetos de colonização que realizou, instituiu políticas de incentivos fiscais e de linhas de crédito para estimular atividades econômicas na região. Essas políticas são descritas nesse item.

Talvez a Amazônia tenha sido a primeira região do Brasil a ter isenção de impostos, visando desenvolver sua atividade econômica, pois tais incentivos surgiram ainda ao longo do século XVII para promover o cultivo do cacau, tabaco e açúcar (Hanson, 1986). Mas é a partir da década de 1960 que os incentivos fiscais se tornam um elemento bastante presente no processo de desenvolvimento da Amazônia.

A concepção e a estrutura das políticas que foram aplicadas na Região Amazônica são derivadas, de certa forma, da experiência que o governo acumulou com a Superintendência de Desenvolvimento do Nordeste (Sudene), criada em 1959. A seu exemplo, em 1966, a Lei n. 5.173 criou a Superintendência de 
Desenvolvimento da Amazônia (Sudam) e extinguiu a Superintendência do Plano de Valorização Econômica da Amazônia (SPVEA). O principal objetivo da Sudam era conceber, promover e coordenar o Plano de Valorização Econômica da Amazônia (PVEA). Além da Sudam, a execução do Plano contava com o Banco da Amazônia S.A. (Basa), demais órgãos do governo federal e também com entidades credenciadas que tinham condições de participar e contribuir para o desenvolvimento da Região Amazônica.

Pelo Decreto-Lei n. 1376/74, o mecanismo do Sistema 34/18, que foi originalmente criado para a Região Nordeste e ampliado também para a Região Norte, tornou-se o Fundo de Investimento da Amazônia (Finam), que continuou a conceder incentivos via dedução do imposto de renda. O Finam ainda se constitui em importante mecanismo para a concessão de incentivos, visando a atração e o desenvolvimento de atividades econômicas na região.

Em relação aos mecanismos utilizados pelo Finam, a Lei n. 8.167 de 16 de janeiro de 1991 alterou a legislação do imposto sobre a renda relativa a incentivos fiscais e estabeleceu novas condições operacionais dos Fundos de Investimentos Regionais. Alguns aprimoramentos foram efetuados por meio dos decretos n. 153, de 25 de junho de 1991, e n. 853, de 2 de julho de 1993; no entanto, a Lei n. 9.532, de 10 de dezembro de 1997, determinou que, a partir de 2003, os incentivos fossem decrescentes até 2013, ano em que os incentivos serão extintos.

Uma importante alteração da política de desenvolvimento da Região Amazônica foi feita por meio da Medida Provisória n. 2.146-1, de maio de 2001, que extinguiu a Superintendência de Desenvolvimento da Amazônia (Sudam). Além disso, ela também criou a Agência de Desenvolvimento da Amazônia (ADA) e o Fundo de Desenvolvimento da Amazônia (FDA), administrado pela ADA e que tem o objetivo de alavancar os recursos necessários para a realização de investimentos nas áreas de atuação das agências. A principal função da ADA é propor e coordenar a implantação do Plano de Desenvolvimento da Amazônia.

A Tabela 1 mostra a evolução dos benefícios concedidos por meio da ADA e Finam. Embora a literatura ressalte o fim das políticas de desenvolvimento regional com a extinção da Sudam, a ADA concedeu um volume maior de benefícios fiscais que o dos últimos anos de vigência da Sudam. O Finam, que, no final da década de 1990, tinha um volume de concessões semelhante ou até mesmo maior que o da Sudam, tem atualmente uma importância relativamente menor que o da ADA. Vale ressaltar que os benefícios fiscais concedidos conjuntamente pelo Finam e ADA, comparando-se 2007 com 2005, tiveram um aumento aproximado de $102 \%$ em termos reais. O montante crescente de benefícios concedidos pela ADA, em especial a partir de 2005 , mostra a intenção do governo em manter a estrutura de desenvolvimento regional ativa. 
Tabela 1

Benefícios fiscais por instituição concedente e setor econômico beneficiado:

1998 a 2007 (R\$ de 2000)

\begin{tabular}{l|r|r|r|r|r|r|r}
\hline \multirow{2}{*}{ Ano } & Total & \multicolumn{3}{|c|}{ Finam } & \multicolumn{2}{c}{ ADA } \\
\cline { 3 - 7 } & & Total & Agropecuária & Indústria & Total & Agropecuária & Indústria \\
\hline 1998 & 1.147 .959 .609 & 553.522 .918 & & & 594.436 .691 & \\
\hline 1999 & 722.472 .273 & 402.459 .960 & & & 320.012 .312 & \\
\hline 2000 & 597.231 .973 & 315.700 .000 & & & 281.531 .973 & \\
\hline 2001 & 614.003 .600 & 342.663 .043 & & & 271.340 .556 & \\
\hline 2002 & 282.872 .110 & & & & 282.872 .110 & \\
\hline 2003 & 670.381 .345 & 136.673 .232 & 25.061 .764 & 111.611 .469 & 533.708 .112 & $97.866 .029,7$ & $435.842 .082,7$ \\
\hline 2004 & 352.382 .864 & 66.102 .841 & 12.121 .275 & $53.981 .566,8$ & 286.280 .023 & $52.495 .153,4$ & $233.784 .869,7$ \\
\hline 2005 & 449.990 .596 & 76.791 .101 & 14.081 .180 & $62.709 .920,3$ & 373.199 .495 & $68.433 .572,9$ & $304.765 .922,9$ \\
\hline 2006 & 583.615 .827 & 99.594 .308 & 18.262 .603 & $81.331 .704,4$ & 484.021 .519 & $88.755 .001,8$ & $395.266 .517,6$ \\
\hline 2007 & 910.402 .954 & 114.270 .510 & 20.953 .778 & $93.316 .732,7$ & 796.132 .443 & 145.986 .766 & $650.145 .677,5$ \\
\hline
\end{tabular}

Fonte: Brasil (1998-2007).

Tabela 2

Valores concedidos pelo Fundo Constitucional de Financiamento do Norte - FNO -

(R\$1000 - valores correntes)

\begin{tabular}{l|r|r|r|r|r|r|r|r}
\hline Estado/Ano & \multicolumn{1}{|c|}{2000} & \multicolumn{1}{|c|}{2001} & \multicolumn{1}{c|}{2002} & \multicolumn{1}{c}{2003} & \multicolumn{1}{c}{2004} & \multicolumn{1}{c}{2005} & \multicolumn{1}{c}{$\begin{array}{c}\text { Total } \\
\text { Acumulado }\end{array}$} \\
\hline Acre & $27.568,0$ & $23.374,1$ & $22.784,3$ & $26.486,0$ & $27.830,6$ & $48.925,6$ & $24.566,9$ & $201.535,50$ \\
\hline Amapá & $5.326,0$ & $4.013,6$ & $4.450,5$ & $2.610,8$ & $4.011,0$ & $5.227,4$ & $3.314,6$ & $28.953,90$ \\
\hline Amazonas & $36.989,0$ & $30.552,5$ & $30.785,3$ & $63.092,4$ & $98.728,5$ & $40.890,0$ & $109.771,8$ & $410.809,50$ \\
\hline Pará & $313.888,0$ & $209.778,1$ & $233.153,4$ & $356.766,8$ & $312.822,5$ & $227.022,8$ & $206.426,5$ & $1.859 .858,10$ \\
\hline Rondônia & $106.813,0$ & $23.311,6$ & $47.309,1$ & $102.048,0$ & $134.977,0$ & $85.555,7$ & $89.475,9$ & $589.490,30$ \\
\hline Roraima & $6.549,0$ & $2.834,2$ & $4.076,5$ & $9.154,1$ & $16.660,0$ & $29.928,0$ & $17.904,4$ & $87.106,20$ \\
\hline Tocantins & $200.178,0$ & $117.122,3$ & $90.930,1$ & $155.349,4$ & $189.060,6$ & $134.929,2$ & $105.726,7$ & $993.296,30$ \\
\hline Total & $697.311,0$ & $410.986,4$ & $433.489,2$ & $715.507,4$ & $784.090,2$ & $572.478,6$ & $557.186,7$ & $4.171 .049,50$ \\
\hline
\end{tabular}

Fonte: Banco da Amazônia (2000-2006). 
A última transformação da estrutura para a formulação de políticas visando o desenvolvimento da Região Norte foi a aprovação do Decreto n. 6.199, de agosto de 2007, que regulamentou o que se denomina a Nova Superintendência do Desenvolvimento da Amazônia (Sudam), extinguindo a Agência de Desenvolvimento da Amazônia (ADA). A nova Sudam está vinculada ao Ministério da Integração Nacional. O mesmo decreto recriou os Conselhos Deliberativos, que têm papel preponderante sobre a formulação de estratégias de desenvolvimento para a região e sobre a aplicação dos recursos dos Fundos de Desenvolvimento da Amazônia (FDA). Com a nova Sudam, o governo pretende manter o aparato das políticas de fomento a atividades econômicas na região. Embora, como se deve supor, as políticas econômicas para o desenvolvimento devam encampar temas ambientais.

A Lei n. 7.827, de 27 de setembro de 1989, criou os Fundos Constitucionais do Norte (FNO), do Nordeste (FNE) e do Centro-Oeste (FCO), que recebem parte dos recursos arrecadados pelo governo federal por meio do Imposto de Renda e do Imposto sobre Produtos Industrializados. A abrangência do FNO é de todos os estados da Região Norte e esse fundo visa fomentar, através de linhas especiais de crédito, o desenvolvimento de atividades econômicas nos setores agropecuário, mineral, industrial, agroindustrial, turístico, comercial e de serviços. A Tabela 2 mostra os valores concedidos pelo FNO para os estados da Região Norte entre 2000 e 2006. Ao longo desse período, o estado que mais recebeu os benefícios foi o Pará ( $\mathrm{R} \$ 1.859 .858 .100)$, seguido de Tocantins ( $\mathrm{R} \$$ 993.296.300) e Rondônia (R\$ 589.490.300).

Para o ano de 2006, 55,7\% dos recursos foram aplicados no setor da agropecuária, $21,4 \%$ no setor industrial, $11,4 \%$ no comércio e prestação de serviços, $11 \%$ em infraestrutura e $0,5 \%$ no turismo.

\section{Análise do comportamento das variáveis consideradas causas imediatas do desmatamento na Amazônia no período de 1970 a 2006}

A literatura ressalta o crescimento populacional, a construção de rodovias e as atividades econômicas (dos setores agropecuário, industrial e de serviços) que são estimuladas pelas políticas econômicas analisadas nos dois últimos itens como causas imediatas do desmatamento. $\mathrm{O}$ presente item analisa a evolução daquelas três variáveis na Amazônia Legal, ressaltando que elas têm dinamismo diferente entre os estados.

Do ponto de vista da ocupação, a Amazônia Legal evoluiu de uma região com população extremamente escassa em 1970 (8,2 milhões habitantes), considerando a sua dimensão territorial, para 17 milhões de habitantes em 1991, até atingir 21 milhões de habitantes em 2000. A densidade demográfica subiu de apenas 1,7 habitante por quilômetro quadrado em 1970 para 4,2 habitantes por quilômetro quadrado em 2000. 
A população urbana de todos os estados que formam a Amazônia Legal teve aumento ao longo de todo o período analisado (ver Gráfico 1). Com exceção de Tocantins, onde a população rural de 2000 é inferior à de 1970, a população rural dos demais estados seguiu a mesma dinâmica que a população urbana. Já entre 1990 e 2000, a população rural aumentou somente no Acre, Amapá, Amazonas, Rondônia e Roraima, tendo diminuído nos outros estados. Vale ressaltar que o número de famílias assentadas, entre 2003 e 2006, na Região Norte, é o maior de todas as regiões do país, totalizando 187.311 famílias nesse período. ${ }^{6}$ Isso mostra o crescimento da população rural e a pressão potencial sobre o desmatamento.

Gráfico 1

População dos estados da Amazônia Legal 1970 a 2000 (mil habitantes)

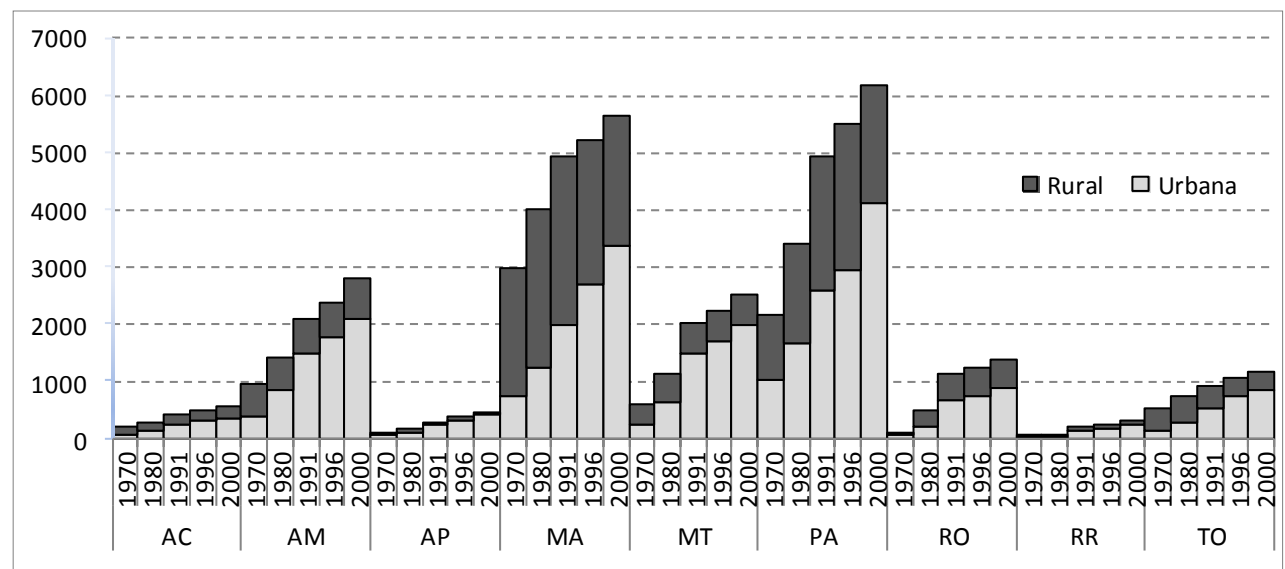

Fonte: IBGE $(2000,2002)$.

Sobre as rodovias, existe certo consenso na literatura de que a abertura ou a pavimentação das existentes facilitam o acesso dos agentes econômicos (como os agricultores) a áreas até então isoladas e diminuem os custos de transporte, ampliando a área destinada à agropecuária e, portanto, o desmatamento (PFAFF, 1996; Laurence et al., 2004; Fearnside, 2006; Fearnside; Graça, 2006; Soares Filho et al., 2005). As rodovias direcionam apenas o sentido do desmatamento, mas a velocidade do desmatamento depende de como os agentes são influenciados positivamente a exercer atividades que demandem solo e que tais atividades sejam alternativas à floresta (Laurance et al., 2004; Soares Filho et al., 2005).

A rede pública de rodovias (federal, estadual e municipal) totalizava aproximadamente 251 mil quilômetros, no ano de 2004, nos estados da Amazônia Legal, dos quais aproximadamente $29 \%$ estavam asfaltados e o restante $(71 \%)$ eram estradas não pavimentadas em diferentes condições de rodagem. Os estados

(6) Incra (8 maio 2007). 
com maior malha rodoviária são os do Mato Grosso, Maranhão e Pará, respectivamente (Gráfico 2).

Embora a economia da Amazônia seja, em certos aspectos, pouco expressiva diante da de outras regiões brasileiras, ela é diversificada e bastante diferenciada entre seus estados. De forma geral, ela é baseada na agropecuária (principalmente na extração de madeira, pecuária e agricultura), na mineração (em especial, de ferro e bauxita), na Zona Franca de Manaus e no setor de serviços. Conforme a Tabela 3, pode-se verificar que o PIB regional totalizou R $\$ 106,7$ bilhões em 2005 (a preços de 2000), o que representou apenas 7,8\% do PIB do Brasil naquele ano.

Gráfico 2

Extensão da malha rodoviária nos estados da Amazônia Legal (100km)

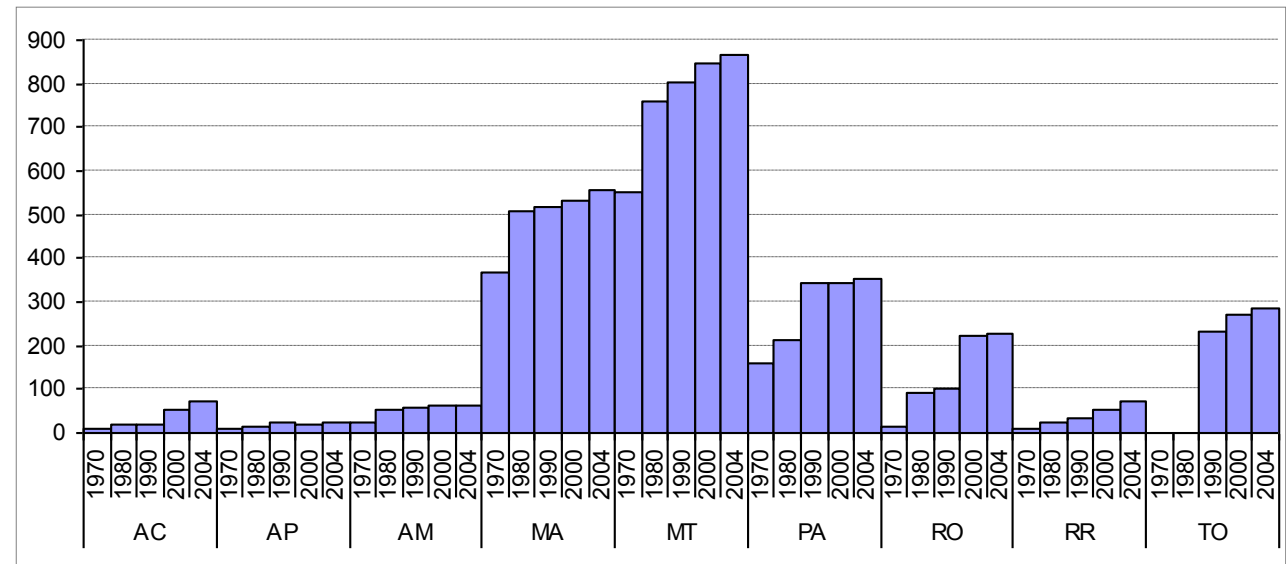

Fonte: Brasil (2001) e Agência Nacional de Transportes Terrestre - ANTT (2006)

Tabela 3

PIB: valor real e composição - 2005 (R\$ de 2000)

\begin{tabular}{l|c|c|c|c}
\hline \multirow{2}{*}{ Estados } & \multirow{2}{*}{ PIB Total (em mil Reais) } & \multicolumn{3}{|c}{ Composição Setorial do PIB (\%) } \\
\cline { 3 - 5 } & & PIB Agropecuário & PIB Industrial & PIB Serviços \\
\hline Acre & $2.824 .255,75$ & 20,02 & 11,52 & 68,45 \\
\hline Amazonas & $21.021 .842,45$ & 5,24 & 44,25 & 50,51 \\
\hline Amapá & $2.751 .652,30$ & 3,20 & 11,38 & 85,42 \\
\hline Maranhão & $15.959 .557,05$ & 17,78 & 17,19 & 65,03 \\
\hline Mato Grosso & $23.609 .976,22$ & 32,17 & 18,66 & 49,17 \\
\hline Pará & $24.671 .384,16$ & 8,95 & 33,14 & 57,91 \\
\hline Rondônia & $8.130 .539,74$ & 20,45 & 13,92 & 65,63 \\
\hline Roraima & $2.003 .060,37$ & 7,66 & 11,05 & 81,29 \\
\hline Tocantins & $5.724 .212,89$ & 21,90 & 27,41 & 50,69 \\
\hline
\end{tabular}

Fonte: Instituto de Pesquisa em Economia Aplicada (Ipea, 2007). 
O setor de serviços é a principal atividade geradora de renda para todos os estados da região e correspondeu, em 2005, a mais de 50\% do PIB para todos os estados que compõem a região (exceto para o Estado do Mato Grosso). Para o Amapá e Roraima, o setor de serviços representou mais de 80\% do PIB em 2005. É importante ressaltar que muitos dos serviços são oriundos das atividades do governo.

Após o setor de serviços, o PIB industrial e o PIB agropecuário assumem pesos distintos para cada um dos estados. Enquanto o PIB industrial tem maior importância que o agropecuário para o Amapá, Amazonas, Pará, Roraima e Tocantins, o PIB agropecuário tem maior peso que o industrial para o Acre, Maranhão, Mato Grosso e Rondônia.

Não há evidências teóricas ou relatos empíricos da relação entre o setor de serviços e o desmatamento. Já a relação entre o desmatamento e o setor industrial é mais clara e, dependendo da natureza da atividade industrial, pode acarretar sérios impactos sobre o desmatamento, como o complexo de Carajás e as empresas que produzem o ferro-gusa no Maranhão e no Pará, que necessitam de carvão para seu processo produtivo. Somente no ano de 2005, há a estimativa de que cem mil hectares de floresta foram derrubados para a produção de carvão vegetal na Amazônia (Homma et al., 2006). Por outro lado, no município de Manaus, onde se localiza a Zona Franca, a área desmatada é uma das menores da região, pois as atividades industriais ali concentradas não demandam bens oriundos da floresta ou grande área antes ocupada por florestas.

De todos os setores, o agropecuário tem o maior impacto sobre o desmatamento dada a sua necessidade por solo. Especificamente sobre ele, o estado com maior importância do PIB agropecuário em 2005 é o de Mato Grosso, seguido pelo Maranhão, Pará e Rondônia (ver Gráfico 3). De 1970 até 2005, o crescimento da produção agropecuária da região não foi contínua, como pode ser observado no Gráfico 3. Entre 2000 e 2005, o PIB agropecuário do Acre cresceu 576,6\%; o do Tocantins, 260\%; o de Roraima, 230\%; o do Amazonas, 134\%; o do Mato Grosso, $106 \%$ e o de Rondônia, $73 \%$. Já o PIB agropecuário do Pará e do Amapá decresceu 51\% e 5,2\%, respectivamente.

Em função do crescimento econômico da região, é factível esperar o aumento dos fatores de produção que são empregados na produção dos bens agropecuários, embora a produtividade dos fatores utilizados possa também ter crescido nesse período. Em todos os estados analisados, a área destinada à agricultura aumentou (ver Gráfico 4) cerca de $220 \%$ entre 1995 e 2006, embora a intensidade do aumento seja bastante diferenciada entre eles.

Em relação à pecuária, com exceção dos estados de Roraima e Tocantins, a área de pastagem dos demais estados aumentou ao longo de todo o período. De forma geral, a pecuária está mais presente nos estados do Mato Grosso, do Pará, Tocantins e Maranhão (Tabela 4). 
Gráfico 3

PIB agropecuário nos estados da Amazônia Legal: 1970 a 2005

(em R\$ milhões a preços de 2000)

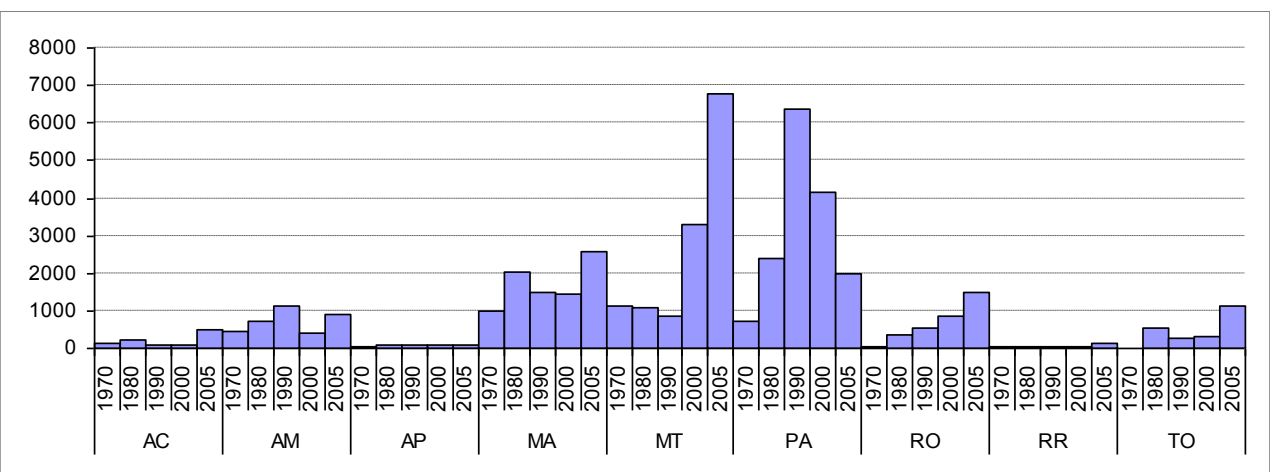

Fonte: Ipea (2007).

Gráfico 4

Área destinada à agricultura e à pastagem nos estados da Amazônia Legal: 1970 a $2006\left(\mathrm{mil} \mathrm{km}^{2}\right)$

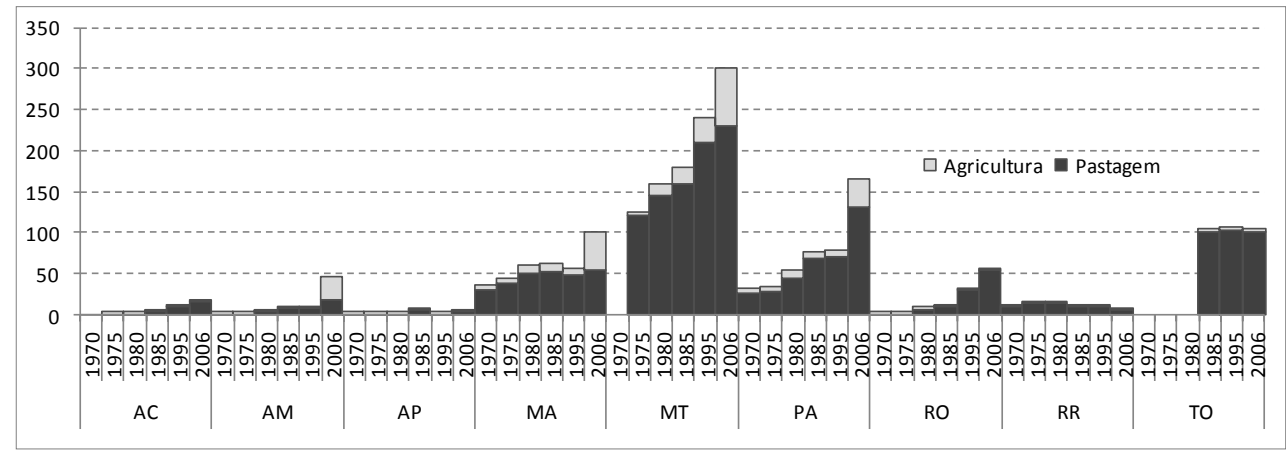

Fonte: IBGE (2006)

Tabela 4

Área destinada à pastagem e à agricultura em 1995 e 2006 e taxas de crescimento dessas áreas $\left(\mathrm{km}^{2}\right)$

\begin{tabular}{|c|c|c|c|c|c|c|}
\hline \multirow{2}{*}{ Estado } & \multicolumn{2}{|c|}{ Pastagem } & \multirow{2}{*}{$\begin{array}{c}\text { Taxa de } \\
\text { Crescimento }\end{array}$} & \multicolumn{2}{|c|}{ Agricultura } & \multirow{2}{*}{$\begin{array}{c}\text { Taxa de } \\
\text { Crescimento }\end{array}$} \\
\hline & 1995 & 2006 & & 1995 & 2006 & \\
\hline Acre & $6.142,13$ & $10.324,31$ & 68,0 & 759,39 & $1.777,32$ & 134,0 \\
\hline Amapá & $2.449,78$ & $4.320,35$ & 76,3 & 198,53 & 838,94 & 322,5 \\
\hline Amazonas & $5.289,13$ & $18.365,35$ & 247,2 & $2.353,61$ & $23.770,48$ & 909,9 \\
\hline Maranhão & $53.105,52$ & $61.626,92$ & 16,0 & $8.218,27$ & $40.775,48$ & 396,1 \\
\hline Mato Grosso & $214.520,61$ & $228.090,21$ & 6,3 & $29.517,45$ & $68.657,63$ & 132,6 \\
\hline Pará & $74.557,28$ & $131.678,56$ & 76,6 & $8.083,54$ & $32.143,31$ & 297,6 \\
\hline Rondônia & $29.220,69$ & $50.642,61$ & 73,3 & $4.323,08$ & $5.134,64$ & 18,7 \\
\hline Roraima & $15.425,65$ & $8.065,59$ & $-47,7$ & $1.330,12$ & $2.284,44$ & 71,7 \\
\hline Tocantins & $110.781,56$ & $102.908,56$ & $-7,1$ & $2.672,28$ & $8.118,74$ & 203,8 \\
\hline
\end{tabular}

Fonte: IBGE (2006). 
Durante todo o período de aceleração do desmatamento (pós 1970), a pecuária tem sido apontada como a principal atividade causadora do desmatamento. Trabalhos realizados na década de 1980 apontavam que a pecuária dominava o uso do solo em áreas desmatadas na Amazônia (Fearnside, 1983).

A pecuária na região vem crescendo desde a década de 1970 quando contava com fortes incentivos fiscais (Fearnside, 1991). Mas, mesmo com menos incentivos a partir do final da década de 1980, a pecuária continuou crescendo na Região Amazônica, passando de cerca de 18,7 milhões de unidades em 1985 para 35 milhões em 1995 e 56 milhões em 2006. Esse crescimento ocorreu devido à melhoria das condições sanitárias de produção, permitindo a exportação para outras regiões do país e também para os mercados internacionais (Nepstad et al., 2006).

A exemplo da área de pastagem, a dimensão do rebanho bovino também aumentou praticamente em todos os estados (ver Gráfico 5). Os principais estados pecuaristas apontados pelo Censo Agropecuário de 2006 são Mato Grosso, Pará, Rondônia, Tocantins e Maranhão.

Gráfico 5

Dimensão do rebanho bovino nos estados da Amazônia Legal: 1970 a 2006 (mil unidades)

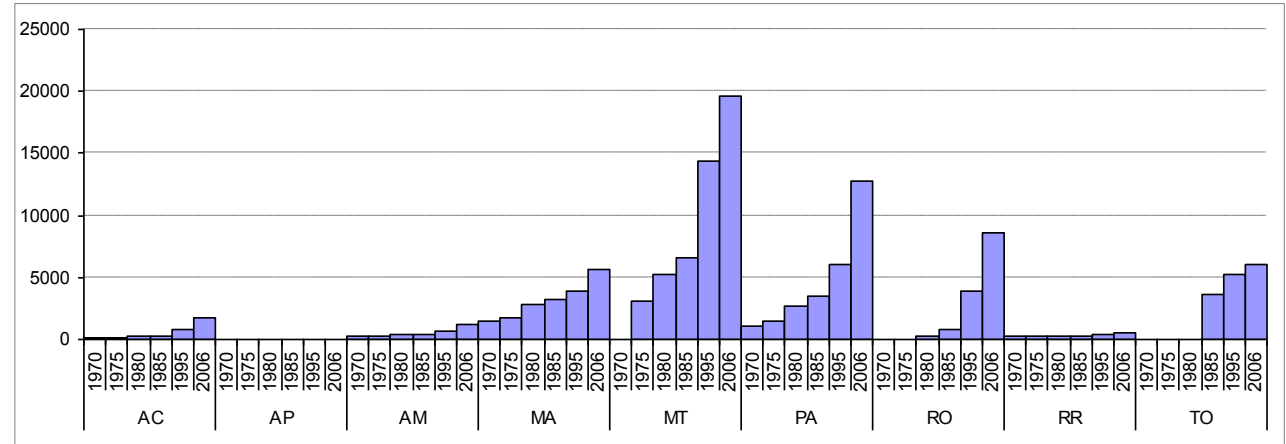

Fonte: IBGE (2006).

Pelo fato de a maior parcela da pecuária ter sido extensiva, seu crescimento implicava necessariamente em desmatamento (Mertens et al., 2002). Como afirma Margulis (2003), a atividade apresenta baixa rentabilidade, e maiores ganhos são obtidos por meio da ampliação das áreas de pastagens, e não pela sua recuperação. O trabalho de Feitosa (2003) aponta que o custo para recuperar áreas de pastagens degradadas é da ordem de $\mathrm{R} \$ 800,00$ por hectare na região sudeste do Estado do Pará, enquanto o custo para gerar novas áreas de pasto a partir do desmatamento é de R \$350,00 por hectare. Dessa forma, existe um estímulo para a continuidade do desmatamento. 
Quando comparada com a pecuária, a influência da agricultura sobre o desmatamento ao longo da década de 1970 foi pequena (Fearnside, 1986). No entanto, a partir da década de 1980, a agricultura praticada pelos colonizadores representava um grande potencial de desmatamento, a chamada agricultura do "corte e queima", principalmente nos estados de Rondônia, Acre e Roraima (Fearnside, 1991).

O desmatamento decorrente do crescimento agrícola é amplamente vinculado aos direitos de propriedade, dos tipos de política utilizada para estimular a agricultura, da credibilidade do governo e se a produção é comercial ou de subsistência. Assim, dependendo das condições que prevalecem, o desmatamento pode ser irrisório ou massivamente destrutivo (López, 2002).

A agricultura das pequenas propriedades, muitas vezes familiar, exerce também grande impacto sobre o desmatamento. De forma geral, a agricultura familiar é itinerante, na medida em que ela está baseada no desmatamento e na queima para o preparo do solo. Quando o solo perde sua capacidade de produção, e isso ocorre em média a cada três anos de uso, os agricultores partem para uma nova área de mata densa (Homma, 2006).

Entre todas as variedades de culturas, a da soja é apontada pela literatura como a grande responsável pelo avanço do desmatamento na Região Amazônica. O cultivo da soja na região não é recente. Ele data de meados da década de 1950, quando o então Instituto Agronômico do Norte realizou alguns experimentos com essa cultura em áreas de várzea em Belém. Em 1982, foi registrada a primeira área para o cultivo comercial da soja, totalizando 60 hectares no Estado de Rondônia. No ano de 1984, a Embrapa Soja recomendou o plantio dessa cultura em Rondônia (Homma, 2003). A partir dessa época, a área ocupada pela soja foi crescente e, em 2005, com exceção do Estado do Amapá, todos os demais produzem soja (ver Tabela 5). É conveniente ressaltar que o cultivo da soja no Estado do Acre apareceu primeiramente nas pesquisas oficiais em 2005.

Tabela 5

Área plantada com soja nos estados da Amazônia Legal: 1990 a 2005

\begin{tabular}{l|c|c|c|c}
\hline Estado/Ano & 1990 & 1995 & 2000 & 2005 \\
\hline Rondônia & 4.640 & 4.500 & 11.800 & 75.275 \\
\hline Acre & 0 & 0 & 0 & 55 \\
\hline Amazonas & 0 & 0 & 1.060 & 2.256 \\
\hline Roraima & 0 & 0 & 0 & 13.000 \\
\hline Pará & 0 & 0 & 2.225 & 68.410 \\
\hline Amapá & 0 & 0 & 0 & 0 \\
\hline Tocantins & 30.120 & 20.237 & 57.919 & 355.300 \\
\hline Maranhão & 15.305 & 87.690 & 178.716 & 372.074 \\
\hline Mato Grosso & 1.552 .910 & 2.338 .926 & 2.906 .648 & 6.121 .724 \\
\hline
\end{tabular}

Fonte: IBGE (1990, 1995, 2000, 2005). 
No entanto, existem outros entendimentos sobre o avanço da soja e o aumento do desmatamento, a exemplo de Brandão, Rezende e Marques (2005). Esses autores salientam que a expansão da área plantada com soja se deu predominantemente pela conversão de áreas de pastagens. Isso é uma evidência de que o avanço da soja não impacta diretamente o desmatamento da floresta amazônica e, sim, é um novo uso para áreas que não conferem níveis satisfatórios de rentabilidade. Mas isto não exclui a sojicultura de ter efeitos indiretos sobre o desmatamento ao compelir o deslocamento da pecuária para novas áreas.

Além da cultura da soja ocupar parcelas crescentes de solo na região, ela necessita da "construção de grandes projetos infra-estruturais, os quais movimentam uma enorme cadeia de eventos condutores da destruição de vastas áreas de habitats naturais" (Fearnside, 2006, p. 264) para muito além da área efetivamente plantada.

De forma geral, o avanço do desmatamento na região também se deve à baixa tecnologia empregada, em boa parte, da produção agropecuária. Convivem na Região Amazônica atividades agropecuárias modernas, com plantadeiras e colheitadeiras e, no outro extremo, atividades arcaicas, que utilizam instrumentos rudimentares de produção. Como as atividades arcaicas sobrevivem somente da incorporação de novas áreas, provenientes da floresta densa, elas, necessariamente, geram novos desmatamentos. Após a derrubada e queima, são plantadas culturas de arroz ou milho, por no máximo 3 anos; em seguida, a área é destinada à pecuária, que se sustenta por cerca de 10 a 12 anos e, após isso, a área é abandonada e as atividades migram para novas áreas de floresta densa (Homma, 2006).

Embora as áreas de pastagem e de agricultura tenham aumentado, a quantidade de pessoas utilizadas na produção agropecuária diminuiu de 1985 a 2006, com exceção do Estado do Mato Grosso, apesar de se expandir de 1970 a 1985 (ver Gráfico 6). Os estados que mais empregam pessoas na atividade agropecuária são Maranhão, Pará, Mato Grosso e Amazonas. Porém, em praticamente todos os estados, houve queda da densidade de trabalhadores, expresso pela relação trabalhadores por área.

A diminuição na quantidade de trabalhadores pode estar atrelada à intensificação de capital utilizado em algumas áreas. O Gráfico 7 mostra a quantidade de tratores utilizados na produção agropecuária e a relação entre a quantidade de tratores e área. 
Gráfico 6

Número de pessoas empregadas na produção agropecuária nos estados da Amazônia Legal: 1970 a 2006 (mil trabalhadores) e relação trabalhadores por unidade de área (trabalhadores por $\mathrm{km}^{2}$ )

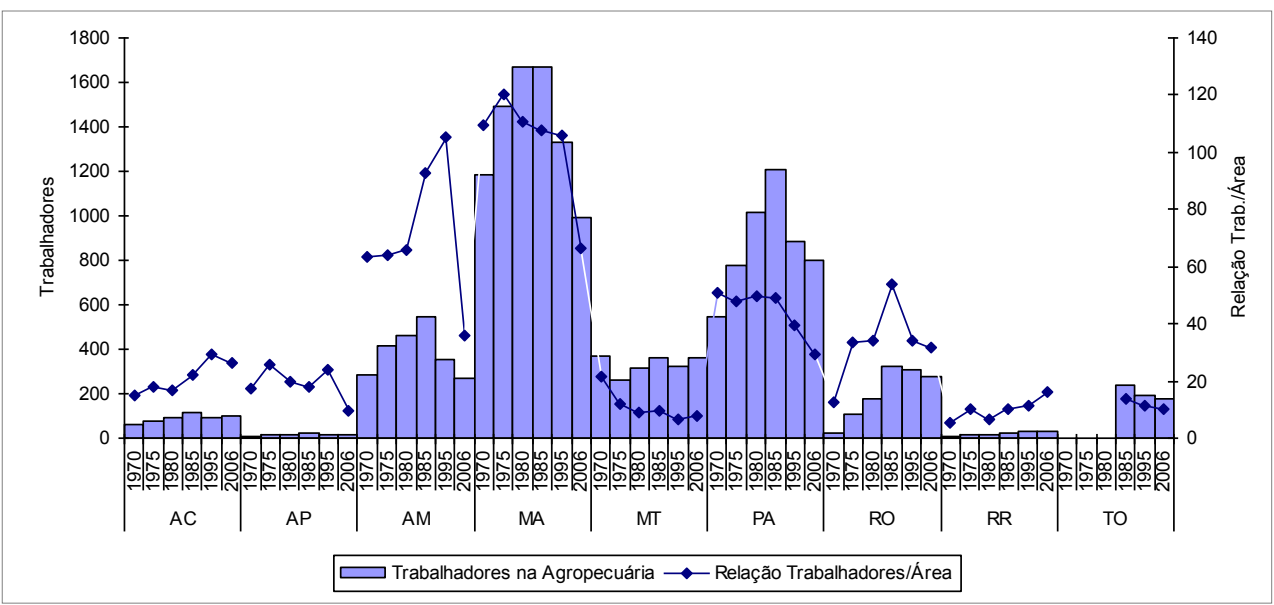

Fonte: IBGE (2006).

Gráfico 7

Número de tratores nos estados da Amazônia Legal: 1970 a 2006 e relação trator/área

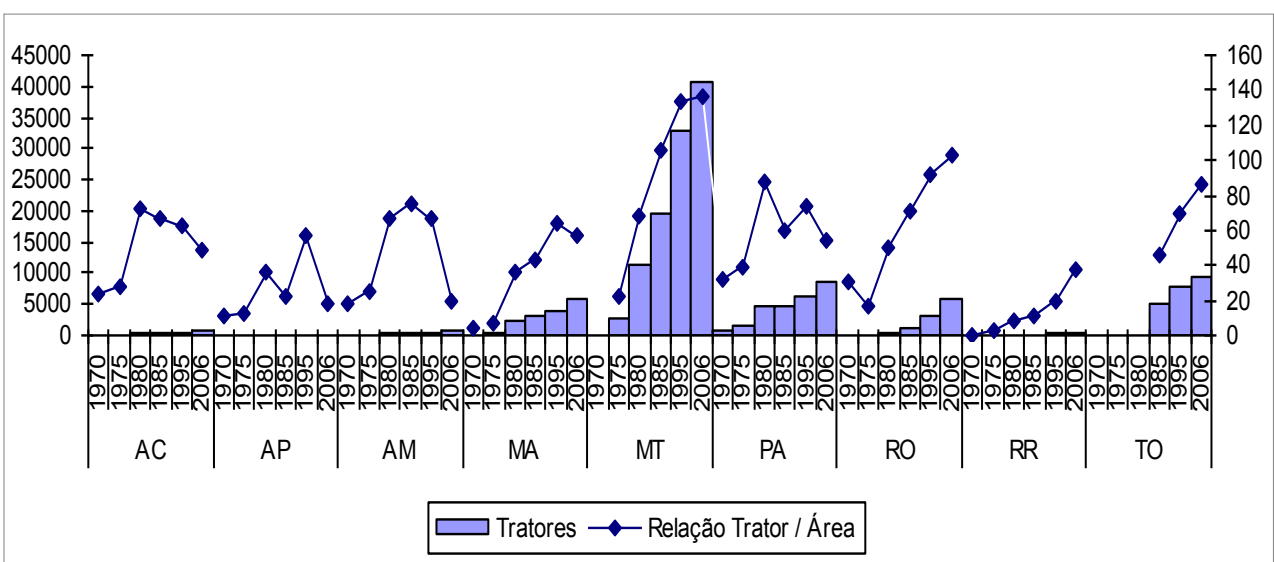

Fonte: IBGE (2006)

Os estados com maior número de tratores, em 2006, foram Mato Grosso, Tocantins, Pará, Maranhão e Rondônia. Além disso, pode-se observar, nos últimos anos, a intensificação do uso de tratores nos estados do Maranhão, Mato Grosso, Rondônia, Roraima e Tocantins. Por outro lado, houve diminuição da relação trator/área nos estados do Acre, Amapá, Amazonas e Pará7.

(7) Apesar de o Gráfico 7 não apresentar os dados sobre o número de tratores no Estado do Amapá, dada a pequena quantidade existente, ele teve um comportamento distinto dos demais estados. Entre 1970 e 1995, o número de tratores cresceu, mas, entre 1995 e 2006, houve diminuição da quantidade de tratores utilizados na produção agropecuária. 
O avanço das atividades agropecuárias implica a substituição de áreas florestais por áreas de cultivo agrícola e de criação pecuária, ou seja, implica o avanço do desmatamento, além da erosão, do assoreamento e poluição dos rios da região.

\section{A evolução recente do desmatamento na Amazônia}

A ocupação da Amazônia, desde a decadência do Ciclo da Borracha, na segunda década do século passado até a década de 1970, produziu o desmatamento em somente $1 \%$ de toda a área. E, nos 35 anos subsequentes, o desmatamento tomou $17 \%$ da área amazônica. A Tabela 6 mostra a evolução do desmatamento para toda a região.

Tabela 6

Evolução da área de cobertura florestal e da área desmatada na Amazônia

\begin{tabular}{|c|c|c|c|}
\hline Período & $\begin{array}{l}\text { Estimativa da cobertura florestal } \\
\text { remanescente na Amazônia } \\
\left(\mathrm{km}^{2}\right)\end{array}$ & $\begin{array}{c}\text { Porcentagem da } \\
\text { cobertura florestal } *\end{array}$ & Área desmatada $\left(\mathrm{km}^{2}\right)$ \\
\hline pré 1970 & 4.100 .000 & 78,58 & \\
\hline 1970 & 4.001 .600 & 76,70 & 98.400 \\
\hline 1977 & 3.955 .870 & 75,82 & 45.730 \\
\hline $1978-1987$ & 3.744 .570 & 71,77 & 211.300 \\
\hline 1988 & 3.723 .520 & 71,37 & 21.050 \\
\hline 1989 & 3.705 .750 & 71,03 & 17.770 \\
\hline 1990 & 3.692 .020 & 70,76 & 13.730 \\
\hline 1991 & 3.680 .990 & 70,55 & 11.030 \\
\hline 1992 & 3.667 .204 & 70,29 & 13.786 \\
\hline 1993 & 3.652 .308 & 70,00 & 14.896 \\
\hline 1994 & 3.637 .412 & 69,72 & 14.896 \\
\hline 1995 & 3.608 .353 & 69,16 & 29.059 \\
\hline 1996 & 3.590 .192 & 68,81 & 18.161 \\
\hline 1997 & 3.576 .965 & 68,56 & 13.227 \\
\hline 1998 & 3.559 .582 & 68,22 & 17.383 \\
\hline 1999 & 3.542 .323 & 67,89 & 17.259 \\
\hline 2000 & 3.524 .097 & 67,54 & 18.226 \\
\hline 2001 & 3.505 .932 & 67,20 & 18.165 \\
\hline 2002 & 3.484 .727 & 66,79 & 21.205 \\
\hline 2003 & 3.459 .576 & 66,31 & 25.151 \\
\hline 2004 & 3.432 .147 & 65,78 & 27.429 \\
\hline 2005 & 3.413 .354 & 65,42 & 18.793 \\
\hline 2006 & 3.400 .254 & 65,17 & 13.100 \\
\hline
\end{tabular}

Nota: *esses valores são subestimados devido ao fato de a área desmatada a cada ano, última coluna da tabela acima, incluir áreas que já foram desmatadas no passado e que estavam cobertas com florestas secundárias.

Fonte: Inpe (2006). 
A Tabela 7 mostra a área desmatada para os estados que compõem a Amazônia Legal no período de 1990 a 2005. Como pode ser observado, existe uma grande discrepância da área desmatada entre os estados. Em função disso, pode-se dividir a região em dois grupos: os estados pouco desmatados e os estados bastante desmatados.

Entre os estados pouco desmatados encontram-se o Acre, Amapá, Amazonas, Maranhão, Roraima e Tocantins. Para o período analisado, 1990 a 2005 , esses estados responderam, em média, por aproximadamente $16 \%$ de todo o desmatamento na Região Amazônica.

Os estados bastante desmatados na Amazônia Legal são Mato Grosso, Pará e Rondônia. A Tabela 8 resume as informações referentes às áreas desmatadas e territoriais de cada estado bem como a porcentagem da área do estado desflorestada entre 1990 e 2005. Nela, pode-se observar que o estado do Mato Grosso foi o que mais teve desmatamento no período analisado, totalizando $12,3 \%$ do seu território. Pará é o segundo maior em desmatamento, 7,3\% do seu território. Rondônia, cuja participação no desmatamento total da Amazônia Legal é bem menor, teve $18 \%$ do seu território desflorestado de 1990 a 2005, pois sua dimensão territorial é bem menor quando comparada com Mato Grosso e Pará.

Tabela 7

Área desmatada nos estados da Amazônia Legal: 1990-2005 (km²/ano)

\begin{tabular}{|c|c|c|c|c|c|c|c|c|}
\hline Estado/Ano & 1990 & 1991 & 1992 & 1993 & 1994 & 1995 & 1996 & 1997 \\
\hline Acre & 550 & 380 & 400 & 482 & 482 & 1.208 & 433 & 358 \\
\hline Amapá & 250 & 410 & 36 & nd & nd & 9 & nd & 18 \\
\hline Amazonas & 520 & 980 & 799 & 370 & 370 & 2.114 & 1.023 & 589 \\
\hline Maranhão & 1.100 & 670 & 1135 & 372 & 372 & 1.745 & 1.061 & 409 \\
\hline Mato Grosso & 4.020 & 2.840 & 4674 & 6.220 & 6.220 & 10.391 & 6.543 & 5.271 \\
\hline Pará & 4.890 & 3.780 & 3787 & 4.284 & 4.284 & 7.845 & 6.135 & 4.139 \\
\hline Rondônia & 1.670 & 1.110 & 2265 & 2.595 & 2.595 & 4.730 & 2.432 & 1.986 \\
\hline Roraima & 150 & 420 & 281 & 240 & 240 & 220 & 214 & 184 \\
\hline Tocantins & 580 & 440 & 409 & 333 & 333 & 797 & 320 & 273 \\
\hline Amazônia Legal & 13.730 & 11.030 & 13.786 & 14.896 & 14.896 & 29.059 & 18.161 & 13.227 \\
\hline Estado/Ano & 1998 & 1999 & 2000 & 2001 & 2002 & 2003 & 2004 & 2005 \\
\hline Acre & 536 & 441 & 547 & 419 & 730 & 885 & 769 & 541 \\
\hline Amapá & 30 & nd & nd & 7 & 0 & 25 & 46 & 33 \\
\hline Amazonas & 670 & 720 & 612 & 634 & 881 & 1.632 & 1.221 & 752 \\
\hline Maranhão & 1.012 & 1.230 & 1065 & 958 & 1.014 & 993 & 755 & 922 \\
\hline Mato Grosso & 6.466 & 6.963 & 6.369 & 7.703 & 7.892 & 10.405 & 11.814 & 7.145 \\
\hline Pará & 5.829 & 5.111 & 6.671 & 5.237 & 7.324 & 6.996 & 8.521 & 5.763 \\
\hline Rondônia & 2.041 & 2.358 & 2.465 & 2.673 & 3.067 & 3.620 & 3.834 & 3.233 \\
\hline Roraima & 223 & 220 & 253 & 345 & 84 & 439 & 311 & 133 \\
\hline Tocantins & 576 & 216 & 244 & 189 & 212 & 156 & 158 & 271 \\
\hline Amazônia Legal & 17.383 & 17.259 & 18.226 & 18.165 & 21.205 & 25.151 & 27.429 & 18.793 \\
\hline
\end{tabular}

nd - dados não disponíveis.

Fonte: Inpe (2006). 
Tabela 8

Área do Estado, Área desmatada acumulada e porcentagem da área desmatada

\begin{tabular}{l|c|c|c}
\hline \multicolumn{1}{c|}{ Estado } & $\begin{array}{c}\text { Área Desmatada } 1990 \mathrm{a} \\
2005 \mathrm{em} \mathrm{km}^{2}\end{array}$ & Área do Estado em $\mathrm{km}^{2}$ & $\begin{array}{c}\text { Porcentagem da Área do } \\
\text { Estado Desmatada 1990 } \\
\text { a 2005 }\end{array}$ \\
\hline Acre & $9.161,2$ & $152.522,0$ & 6,0 \\
\hline Amapá & 864,0 & $142.815,8$ & 0,6 \\
\hline Amazonas & $13.887,2$ & $1.570 .946,8$ & 0,9 \\
\hline Maranhão & $14.813,3$ & $331.918,0$ & 4,5 \\
\hline Mato Grosso & $110.936,3$ & $903.386,1$ & 7,3 \\
\hline Pará & $90.595,8$ & $1.247 .702,7$ & 18,0 \\
\hline Rondônia & $42.674,4$ & $237.564,5$ & 1,8 \\
\hline Roraima & $3.957,4$ & $224.118,0$ & 2,0 \\
\hline Tocantins & $5.506,9$ & $277.297,8$ & \\
\hline
\end{tabular}

Fonte: Inpe (2006) e Atlas do Desenvolvimento Humano (2003).

O Estado do Amapá pode ser considerado, com a ressalva da inexistência de dados em alguns anos, como o que menos teve desmatamento no período analisado, seguido por Roraima e Tocantins (Tabela 8). Por sua vez, os estados bastante desmatados, que são Mato Grosso, Pará e Rondônia, são responsáveis, em média, por aproximadamente $84 \%$ do desflorestamento na Amazônia.

Os dados da Tabela 9 permitem verificar que o processo de desmatamento na Amazônia Legal é desigual também entre os seus municípios.

Tabela 9

Localização dos municípios com maior área de desmatamento anual até o ano de 2005

\begin{tabular}{l|c|c|c|c}
\hline \multirow{2}{*}{ Estado } & \multicolumn{4}{|c}{ Número de municípios } \\
\cline { 2 - 5 } & $10+$ & $20+$ & $50+$ & $100+$ \\
\hline Acre & 0 & 0 & 1 & 1 \\
\hline Amapá & 0 & 0 & 0 & 0 \\
\hline Amazonas & 0 & 0 & 0 & 0 \\
\hline Maranhão & 2 & 2 & 3 & 37 \\
\hline Mato Grosso & 1 & 8 & 18 & 37 \\
\hline Pará & 7 & 9 & 22 & 12 \\
\hline Rondônia & 0 & 1 & 5 & 0 \\
\hline Roraima & 0 & 0 & 0 & 3 \\
\hline Tocantins & 0 & 0 & 1 & .
\end{tabular}

Nota: $10+=$ dez municípios com maior área desmatada; $20+=$ vinte municípios com maior área desmatada e assim por diante.

Fonte: Inpe (2006). 
Conforme pode ser visto na Tabela 9, dos 10 municípios com maior área de desmatamento anual até 2005, 7 deles concentravam-se no Estado do Pará, 2 no Maranhão e 1 no Mato Grosso. Particularmente, os dois municípios com maior área de desmatamento estão no Pará: São Félix do Xingu e Marabá, respectivamente. Entre os 20 municípios com maior área desmatada, 9 se concentram no Pará e 8 no Mato Grosso. Na medida em que se amplia o número de municípios com maior desmatamento dentro da análise, outros estados começam a aparecer. Vale ressaltar que, entre os 100 municípios com as maiores áreas de desmatamento, nenhum deles está localizado nos estados do Amapá, Amazonas e Roraima.

Finalmente, é importante ressaltar que o desmatamento somente ocorre em áreas onde há floresta (primária ou secundária) e, em muitos municípios da Amazônia, praticamente não existe mais florestas; assim, tais municípios não irão entrar nas estatísticas mais recentes de desmatamento, pois, neles, o desmatamento já ocorreu em períodos passados.

A Tabela 10 apresenta, para cada estado da Amazônia Legal, o número de municípios por classe de área desmatada.

A realidade do ano de 2005 evidencia que 13,6\% dos municípios da Amazônia já tinham desmatado mais de $95 \%$ de sua cobertura florestal; $16 \%$ dos municípios apresentavam entre $75 \%$ e $94,9 \%$ de área desmatada; $14,8 \%$ deles estavam entre $50 \%$ e $74,9 \% ; 19,8 \%$ entre $25 \%$ e $49,9 \%$; e $35,8 \%$ com menos de $25 \%$ de sua cobertura florestal já desmatada.

Tabela 10

Número de municípios em cada estado por classes de área desmatada - Ano de 2005

\begin{tabular}{l|r|r|r|r|r|r|r|r|r|r|r}
\hline & $>95 \%$ & $(\%)$ & $\begin{array}{r}75 \% \text { a } \\
94,9 \%\end{array}$ & $(\%)$ & $\begin{array}{r}50 \% \mathrm{a} \\
74,9 \%\end{array}$ & $\mathbf{( \% )}$ & $\begin{array}{c}25 \% \\
49,9 \%\end{array}$ & $\mathbf{( \% )}$ & $\begin{array}{c}0 \mathrm{a} \\
25 \%\end{array}$ & $\mathbf{( \% )}$ & Total \\
\hline Acre & 0 & 0,0 & 0 & 0,0 & 3 & 13,6 & 6 & 27,3 & 13 & 59,1 & 22 \\
\hline Amapá & 0 & 0,0 & 0 & 0,0 & 0 & 0,0 & 2 & 12,5 & 14 & 87,5 & 16 \\
\hline Amazonas & 0 & 0,0 & 0 & 0,0 & 1 & 1,6 & 8 & 12,9 & 53 & 85,5 & 62 \\
\hline Maranhão & 37 & 19,1 & 49 & 25,3 & 41 & 21,1 & 33 & 17,0 & 34 & 17,5 & 194 \\
\hline Mato Grosso & 1 & 0,7 & 18 & 12,9 & 14 & 10,1 & 41 & 29,5 & 65 & 46,8 & 139 \\
\hline Pará & 30 & 21,0 & 24 & 16,8 & 30 & 21,0 & 27 & 18,9 & 32 & 22,4 & 143 \\
\hline Rondônia & 0 & 0,0 & 15 & 28,8 & 11 & 21,2 & 18 & 34,6 & 8 & 15,4 & 52 \\
\hline Roraima & 0 & 0,0 & 0 & 0,0 & 0 & 0,0 & 1 & 6,7 & 14 & 93,3 & 15 \\
\hline Tocantins & 38 & 27,3 & 19 & 13,7 & 16 & 11,5 & 19 & 13,7 & 47 & 33,8 & 139 \\
\hline Total & 106 & 13,6 & 125 & 16,0 & 116 & 14,8 & 155 & 19,8 & 280 & 35,8 & 782 \\
\hline
\end{tabular}

Fonte: Inpe (2006).

Entre os estados, aproximadamente $27 \%$ dos municípios do Tocantins, $21 \%$ dos municípios do Pará e 19\% dos municípios do Maranhão tinham mais de 
95\% de suas áreas desmatadas em 2005. Na segunda classe, entre 75\% e 94,9\%, estavam 28,8\% dos municípios de Rondônia, 25,3\% dos do Maranhão, 16,8\% dos do Pará, $13,7 \%$ dos do Tocantins e $12,9 \%$ dos do Mato Grosso. Na terceira classe, entre $50 \%$ e 74,9\%, estavam, praticamente em igualdade, Rondônia, Maranhão e Pará, com aproximadamente $21 \%$ de seus municípios, Acre com 13,6\%, Tocantins com $11,5 \%$, Mato Grosso com 10,1\% e Amazonas com 1,6\%. Já na quarta classe, entre $25 \%$ e $49,9 \%$, estavam $34,6 \%$ dos municípios de Rondônia, $29,5 \%$ dos do Mato Grosso, 27,3\% dos do Acre, 18,9\% dos municípios do Pará, 17\% dos do Maranhão, 13,7\% dos do Tocantins, 12,9\% dos municípios do Amazonas, 12,5 dos do Amapá e 6,7\% de Roraima. E, finalmente, na última classe, entre zero e 25\%, encontram-se 93,3\% dos municípios de Roraima, 87,5\% dos do Amapá, 85,5\% dos do Amazonas, 59,1\% dos do Acre, 46,8\% dos do Mato Grosso, 33,8\% dos do Tocantins, 22,4\% dos municípios do Pará, 17,5\% dos municípios Maranhão e 15,4\% dos municípios de Rondônia. Observe-se que os estados considerados bastante desmatados ainda possuem municípios em que a área desmatada é pequena.

\section{Considerações finais}

Nos últimos quarenta anos, a Amazônia vem passando por um grande processo de transformação, marcado pelo aumento de sua relação econômica com as demais regiões do país e também por sua maior inserção internacional, que define uma nova dinâmica populacional, econômica e, consequentemente, ambiental para a região.

Até chegar à caracterização atual, a região passou por várias fases. A dinâmica da economia da região, no período de 1946 a meados da década de 1960, foi marcada pelo aproveitamento dos recursos naturais sem a ocorrência de grandes danos ambientais em relação a sua dotação existente, exceto em áreas mais específicas. Já a fase de intervenção do regime militar, em meados da década de 1960 a meados da década de 1980, gerou, além de projetos e programas específicos de desenvolvimento, a abertura de frentes que estimularam o crescimento populacional e econômico, contribuindo para o desmatamento das áreas florestais.

As políticas públicas que visavam o desenvolvimento da região classificam-se em: a) as direcionadas para o desenvolvimento específico da região, como as políticas fiscais e de infraestrutura e b) as de abrangência nacional, que se desdobravam sobre a região, a exemplo dos PNDs, do PIN e do Proterra.

As ações públicas sobre a Região Amazônica, principalmente no período do governo militar, não buscaram engendrar ações que harmonizassem as dimensões ambientais, sociais, políticas e econômicas de promoção do 
desenvolvimento. A política de desenvolvimento, pelo contrário, esteve marcada por ações setoriais que, além de se constituírem discriminatórias, a exemplo das concessões de financiamento prioritariamente aos grandes empreendimentos econômicos, eram ambientalmente e socialmente agressivas, o que pode ser comprovado pelo avanço do desmatamento e dos conflitos entre grileiros e posseiros.

Embora o governo, principalmente nos 20 anos, entre 1965 e 1985, tenha adotado uma política de planejamento territorial, ela careceu de um conhecimento mais apurado do meio físico, que oferecesse realmente suporte às suas ações, pois muitas das políticas geraram resultados insuficientes às propostas originais, como é o caso dos assentamentos de colonos.

A etapa atual de desenvolvimento da Amazônia é marcada pelo estímulo de mercado, em que é indiscutível a importância dos madeireiros, dos pecuaristas e dos agricultores, esses últimos, principalmente, pelo cultivo da soja. O Estado ainda detém o controle do território, no entanto, ao contrário das décadas anteriores, em que o governo definia o uso da terra, são as empresas que atualmente o determinam. A somatória de todos esses agentes que especificam o uso do solo traduz-se no avanço do desenvolvimento da região e, consequentemente, na progressão do desmatamento. No entanto, o desenvolvimento e o desmatamento da Amazônia são processos desiguais entre os estados que a compõem e também entre os municípios que integram cada estado. Isso ocorre pelo fato de as atividades econômicas e a dinâmica populacional terem intensidades e evolução diferentes no espaço.

Por meio de dados secundários, pode-se perceber a dinâmica do processo de desenvolvimento da região e como esse desenvolvimento se manifestou entre os estados da Amazônia. As atividades econômicas predominantes, a exemplo do setor de serviços, não têm impactos diretos sobre o desmatamento; por sua vez, a agropecuária, que é a responsável por parcela expressiva do PIB da região, tem fortes ligações com o desmatamento, dada sua dependência por terras. Ademais, é possível afirmar que existe uma correlação entre outras atividades humanas exercidas na região e o seu desmatamento, como é o caso de algumas atividades industriais.

A constatação de que o desmatamento da Amazônia Legal é desigual entre os estados e também entre seus municípios suscita alguns pontos que necessitam ser melhor explorados, tais como, determinar quais os fatores mais atuantes para explicar o desmatamento em cada estado. Isto é possível, estimando um modelo econométrico para explicar o desmatamento dos estados e de seus municípios, o que fica como sugestão para futuros trabalhos. 


\section{Referências bibliográficas}

AGÊNCIA NACIONAL DE TRANSPORTE TERRESTRE - ANTT. Anuário estatístico 2004. Disponível em: http://www.antt.gov.br/passageiro/anuarios/anuario2004/default.htm Acesso em: 19 jan. 2007.

BANCO DA AMAZÔNIA. Relatório de gestão: exercício 2001. Belém, 2002. 56p. Disponível em: http://www.basa.com.br/bancoamazonia2/includes/investidores/arquivos/ processo de contas/banco/rg01.pdf. Acesso em: 21 jan. 2007.

BANCO DA AMAZÔNIA. Relatório de gestão: exercício 2002. Belém, 2003. 32p. Disponível em: http://www.basa.com.br/bancoamazonia2/includes/investidores/arquivos/ processo_de_contas/banco/rg02.pdf. Acesso em: 21 jan. 2007.

BANCO DA AMAZÔNIA. Relatório de gestão: exercício 2003. Belém, 2004. 24p. Disponível em: http://www.basa.com.br/bancoamazonia2/includes/investidores/arquivos/ processo_de_contas/banco/rg03.pdf. Acesso em: 21 jan. 2007.

BANCO DA AMAZÔNIA. Relatório de gestão: exercício 2004. Belém, 2005. 109p. Disponível em: http://www.basa.com.br/bancoamazonia2/includes/investidores/arquivos/ processo_de contas/banco/rg04.pdf. Acesso em: 21 jan. 2007.

BANCO DA AMAZÔNIA. Relatório de gestão: exercício 2005. Belém, 2006. 46p. Disponível em: http://www.basa.com.br/bancoamazonia2/includes/investidores/arquivos/ processo de contas/banco/rg05.pdf. Acesso em: 21 jan. 2007.

BECKER, B. K. Geopolítica da Amazônia. Estudos Avançados, São Paulo, v. 19, n. 53, p. 71-86, 2005.

. Reflexões sobre a geopolítica e a logística da soja na Amazônia. In: COSTA, W.M.; BECKER, B.K.; ALVES, D.S. (Org.). Dimensões humanas da biosfera-atmosfera na Amazônia. São Paulo: Edusp, 2007. p. 13-38.

- Reflexões sobre políticas de integração nacional e de desenvolvimento regional. In: KINGO, M. D. (Org.). Reflexões sobre políticas de integração nacional e de desenvolvimento regional. Brasília: Ministério da Integração Nacional, 2000. p. 71-138.

- Revisão das políticas de ocupação da Amazônia: é possível identificar modelos para projetar cenários? Parcerias Estratégicas, Brasília, v. 12, n. 1, p. 135-159, set. 2001.

BENCHIMOL, J. L. Origens e evolução do Instituto Oswaldo Cruz no período 18991937. In: BENCHIMOL, J. L. (Coord.). Manguinhos do sonho à vida: a ciência na belle époque. Rio de Janeiro: Fiocruz, 1990. p. 5-88.

. Amazônia: formação social e cultural. Manaus: Editora Valer, 1999. 480p.

BRANDÃO, A. S. P.; REZENDE, G. C.; MARQUES, R. W. C. Agricultural growth in the period 1999-2004, outburst in soybeans area and environmental impacts in Brazil. Rio de Janeiro: Ipea, 2005. 35p. (Texto para Discussão, 1062). 
BRASIL. Ministério da Ciência e Tecnologia. Projeto de estimativa de desflorestamento da Amazônia - PRODES. Disponível em: http://www.obt.inpe.br/prodes. Acesso em: 12 jan. 2007.

BRASIL. Ministério da Fazenda. Secretaria do Tesouro Nacional. Relatório de Atividades 1998 a 2007. Brasília, 2007. 115p.

BRASIL. Ministério da Integração Nacional; Ministério do Meio Ambiente. Comissão de Coordenação Interinstitucional. Plano Amazônia sustentável. Brasília, 2006. 171p. Disponível em: http://www.mma.gov.br/estruturas/sca/_arquivos/pas_versao_consulta _com_os_mapas.pdf.

BRASIL. Ministério dos Transportes. Empresa Brasileira de Planejamento de Transportes - GEIPOT. Anuário estatístico dos transportes: Sistema de Informações do Anuário Estatístico dos Transportes - SISAET, 1999, 2000. Disponível em: http://www.geiport.gov.br/anuário2000. Acesso em: 13 jan. 2007.

CARDOSO, F. H.; MULLER, F. Amazônia: expansão do capitalismo. In: SOUZA, E. A. Sinop: história, imagens e relatos: um estudo sobre a colonização de Sinop. Cuiabá: UFMT, 2001. 58p.

COSTA, W. M. Geografia política e geopolítica: discursos sobre o território e o poder. São Paulo: Hucitec/Edusp, 1992. 374p.

COUTO E SILVA, G. Conjuntura política nacional: o poder executivo \& geopolítica do Brasil. Rio de Janeiro: José Olympio, 1981. 275p.

FEARNSIDE, P. M. Desmatamento e desenvolvimento agrícola na Amazônia brasileira. Amazônia: a fronteira agrícola 20 anos depois. Belém: Museu Paraense Emílio Goeldi, 1991.363p.

. Land-use trends in the Brazilian Amazon region as factors in accelerating deforestation. Environment Conservation, Newcastle-upon-Tyne, v. 10, n. 2, p. 141-148, 1983.

- O cultivo da soja como ameaça para o meio ambiente na Amazônia brasileira. In: FORLINE, L.; MURRIETA, R. (Ed.). Amazônia 500 anos: o V centenário e o novo milênio: lições de história e reflexões para uma nova era. Belém: Museu Paraense Emílio Goeldi, 2006. p. 263-306.

. Os planos agrícolas: desenvolvimento para quem e por quanto tempo? In: ALMEIDA JÚNIOR, M. G. Carajás: desafio político, ecologia e desenvolvimento. São Paulo: Brasiliense, 1986. p. 362-418.

; GRAÇA, P. M. L. A. BR-319: Brazil's Manaus-Porto Velho highway and the potential impact of linking the arc of deforestation to central Amazonia. Environmental Management, NewYork, v. 38, n. 2, p. 705-716, 2006.

FEITOSA, T. C. Análise da sustentabilidade na produção familiar no sudeste paraense: o caso dos produtores de leite do município de Rio Maria. 2003. 173p. Dissertação 
(Mestrado em Agriculturas Familiares e Desenvolvimento Sustentável)-Universidade Federal do Pará, Belém, 2003.

FIGUEIREDO, A. M.; LOPES, M. L. B.; FILGUEIRAS, G. C. Extração de madeira e agregação ao PIB da Região Amazônica. Amazônia: Ciência \& Desenvolvimento, Belém, v. 1, n. 1, p. 83-93, jul./dez. 2005.

FURTADO, C. Formação econômica do Brasil. São Paulo: Companhia Editora Nacional, 1991. 248p.

GOMES, G. M.; VERGOLINO, J. R. Trinta e cinco anos de crescimento econômico na Amazônia (1960/1995). Brasília: Ipea, 1997, 144p. (Texto para Discussão, 533).

GOODLAND, R. J. A.; IRWIN, H. S. Amazon jungle: green hell to red desert: an ecological discussion of the environmental impact of the highway construction program in the Amazon Basin. NewYork: Elsevier Scientific Publishing, 1975. 155p.

GUILHOTO, J. J. M.; SESSO FILHO, U. A. Análise da estrutura produtiva da Amazônia brasileira. Amazônia: Ciência \& Desenvolvimento, Belém, v. 1, n. 1, p. 7-33, jul./dez. 2005.

HANSON, C. Economia e sociedade no Portugal barroco. Lisboa: Quixote, 1986. 330p.

HOMMA, A. K. O. Agricultura familiar na Amazônia: a modernização da agricultura itinerante. In: SOUSA, I. S. F. (Ed.). Agricultura familiar na dinâmica da pesquisa agropecuária. Brasília: Embrapa Informação Tecnológica, 2006. p. 33-60.

- História da agricultura na Amazônia: da era pré-colombiana ao terceiro milênio. Brasília: Embrapa Informação Tecnológica, 2003. 52p.

. Produção rural: empresarial e familiar. Belém: Universidade Federal do Pará, 2006. 9v. Disponível em: http://www.ada.gov.br/index.php?Itemid=73\&id=48\&option $=$ com_content\&task=view. Acesso em: 10 jan. 2007.

; ALVES, N. R. B.; MENEZES, A. J. E. A.; MATOS, G B. Guseiras na Amazônia: perigo para a floresta. Ciência Hoje, Rio de Janeiro, v. 39, n. 233, p. 56-63, 2006.

INSTITUTO BRASILEIRO DE GEOGRAFIA E ESTATÍSTICA - IBGE. Censo agropecuário 2006: resultados preliminares. Rio de Janeiro: IBGE, 2006.

. Censo demográfico 2000. Rio de Janeiro: IBGE, 2002.

- Sistema IBGE de recuperação automática (Sidra). Disponível em: http://www.sidra.ibge.gov.br. Acesso em: 15 jan. 2007.

INSTITUTO DE PESQUISA ECONÔMICA APLICADA - IPEA. Ipeadata. Disponível em: http://www.ipeadata.gov.br. Acesso em: 20 mar. 2007.

INSTITUTO NACIONAL DE COLONIZAÇÃO E REFORMA AGRÁRIA - INCRA. Sistema de Informações de Projetos de Reforma Agrária - SIPRA. Relatório: 0227 de 8 de maio de 2007. 
INSTITUTO NACIONAL DE PESQUISAS ESPACIAIS - INPE. Monitoramento da floresta amazônica brasileira por satélite: Projeto Prodes. São José dos Campos: Inpe, 1979. Disponível em: http://www.obt.inpe.br/prodes/index.html. Acesso em: 15 jan. 2007.

KAIMOWITZ, D.; MERTENS, B.; WUNDER, S.; PACHECO, P. A conexão hambúrguer alimenta a destruição da Amazônia: desmatamento e pecuária na Amazônia. Jakarta: CIFOR, 2004. Disponível em: http://www.cifor.cgiar.org/publications/pdf_files/media/ Amazon-Portugese.pdf. Acesso em: 20 abr. 2007.

KOHLHEPP, G. Conflitos de interesse no ordenamento territorial da Amazônia brasileira. Estudos Avançados, São Paulo, v. 16, n. 45, p. 37-61, 2002.

LAURANCE, W. F.; ALBERNAZ, A. K. M.; FEARNSIDE, P. M.; VASCONCELOS, H. L.; FERREIRA, L. V. Deforestation in Amazonia. Science, Washington, n. 304, p. 1109$1111,2004$.

LÓPEZ, R. A note on the environmental effects of agricultural expansion: theoretical note. ROA Publication, Rome, v. 2, n. 3, p. 77-92, 2002.

MARGULIS, S. Causas do desmatamento da Amazônia brasileira. 1. ed. Brasília: Banco Mundial, 2003. 100p.

MEIRA MATTOS, C. Geopolítica Pan-Amazônica. Rio de Janeiro: Biblioteca do Exercito - BIBLIEX, 1980. 216p.

MENEZES, A. J. E. A. de. Análise econômica da "produção invisível" nos estabelecimentos agrícolas familiares no Projeto de Assentamento Agroextrativista Praialta e Piranheira, município de Nova Ipixuna, Pará. 2005. 130p. Dissertação (Mestrado em Agriculturas Familiares e Desenvolvimento Sustentável)-Universidade Federal do Pará, Belém, 2002.

MERTENS, B.; POCCARD-CHAPUIS, R.; PIKETTY, M. G.; LACQUES, A. E.; VENTURIERI, A. A crossing spatial analyses and livestock economics to understand deforestation processes in the Brazilian Amazon: the case of São Félix do Xingu in South Pará. Agricultural Economics, West Lafayette, v. 27, n. 1, p. 269-294, 2002.

MIRANDA NETO, M. O enigma amazônia: desafio ao futuro. Belém: CEJUP, 1991. 143p.

MOREIRA, M.; MOURA, H. As migrações na região norte em periodo recente: uma abordagem preliminar. Manaus: IESAM/Fundação Joaquim Nabuco, 1998. 71p. (Texto IESAM, 1).

NASCIMENTO, C.; HOMMA, A. Amazônia: meio ambiente e tecnologia agrícola. Belém: CPATU, 1984. 282p. (EMBRAPA-CPATU. Documento 27).

NEPSTAD, D.C.; STICKLER, C. M.; ALMEIDA, O. T. Globalization of the Amazon soy and beef industries: opportunities for conservation. Conservation Biology, Malden, v. 20, p. 1595-1603, 2006. 
PFAFF, A.S.P. What drives deforestation in the Brazilian Amazon? MIT Joint Program on the Science and Policy of Global Change. Cambridge, 1996. 32p. Disponível em: http://web.mit.edu/globalchange/www/rpt16.html. Acesso em: 15 maio 2007.

PRADO JÚNIOR, C. História econômica do Brasil. São Paulo: Editora Brasiliense, 1993. $364 \mathrm{p}$.

PROGRAMA DAS NAÇÕES UNIDAS PARA O DESENVOLVIMENTO - PNUD. Atlas do desenvolvimento humano no Brasil. Disponível em: http://www.pnud.org.br/atlas/. Acesso em: 3 mar. 2007.

REBELLO, F. K.; HOMMA, A. K. O. Uso da terra na Amazônia: uma proposta para reduzir desmatamentos e queimadas. Ciência \& Desenvolvimento, Belém, v. 1, n. 1, p. 199-236, jul./dez. 2005.

REIS, M. S. Uma definição técnica-política para o aproveitamento racional dos recursos florestais da Amazônia brasileira. Brasília: Instituto Brasileiro de Desenvolvimento Florestal, 1978. 21p.

REYDON, B. P. Agricultura sustentável: uma agenda para o desenvolvimento de produção economicamente viável para a Região Amazônica. In: ROMEIRO, A. R.; REYDON, B. P.; LEONARDI, M. L. A. (Org.). Economia do meio ambiente: teoria, políticas e a gestão de espaços regionais. Campinas, SP: Unicamp, Instituto de EconomiaIE, 1997. p. 299-309.

ROSS, J. L. S. Ecogeografia do Brasil: subsídios para planejamento. São Paulo: Oficina de Textos, 2006. 207p.

SERRA, M. A.; FERNÁNDEZ, R. G. Perspectivas de desenvolvimento da Amazônia: motivos para o otimismo e para o pessimismo. Economia e Sociedade, Campinas, v. 13, n. 2, p. 1-25, 2004.

SERRÃO, E. A. S.; FALESI, I. C.; VEIGA, J. B. da; TEIXEIRA NETO, J. F. Produtividade de pastagens cultivadas em solos de baixa fertilidade das áreas de floresta do trópico úmido brasileiro. Belém: Empresa Brasileira de Pesquisa Agropecuária. Centro de Pesquisa Agropecuária do Trópico Úmido, 1978. 73p.

SILVA, L. M. S.; RODRIGUEZ, L. C. E.; GUILHOTO, J. J. M. Dependência econômica do Acre: o mais ocidental estado amazônico no Brasil: com relação a outras regiões. Submitted to the II Latin American Symposium on Forest Management and Economics, 2004, Barcelona.

SOARES-FILHO, B. S.; NEPSTAD, D.C.; CURRAN, L. Cenários de desmatamento para a Amazônia. Estudos Avançados, São Paulo, v. 19, n. 54, p. 137-152, 2005.

SOUZA, M. Amazônia e modernidade. Estudos Avançados, São Paulo, v. 45, n. 15, p. 31$36,2002$.

TARDIN, A. T.; SANTOS, A. P.; LEE, D. C. L.; MAIA, F. C. S.; MENDONÇA, F. J.; ASSUNÇÃO, G. V.; RODRIGUES, J. E.; ABDON, M. M.; NOVAES, R. A.; CHEN, S. C.; DUARTE, V.; SHIMABUKURO, Y. E. Levantamento de áreas de desmatamento na 
Rodolfo Coelho Prates / Carlos José Caetano Bacha

Amazônia Legal através de imagens do Satélite LANDSAT. São José dos Campos: Inpe, 1979. 142 p.

TEIXEIRA, G. Amazônia: estado, exclusão social e devastação. Brasília: Câmara dos Deputados, jun. 1998. 12p.

THÉRY, H. A Amazônia no Brasil: peso econômico, social e estratégico. In: JORNADAS AMAZÔNICAS, 3, 2002, Brasília.

WEINHOLD, D.; REIS, E. Land use and transportation costs in the Brazilian Amazon. Rio de Janeiro: Ipea, 2003. 31p. 